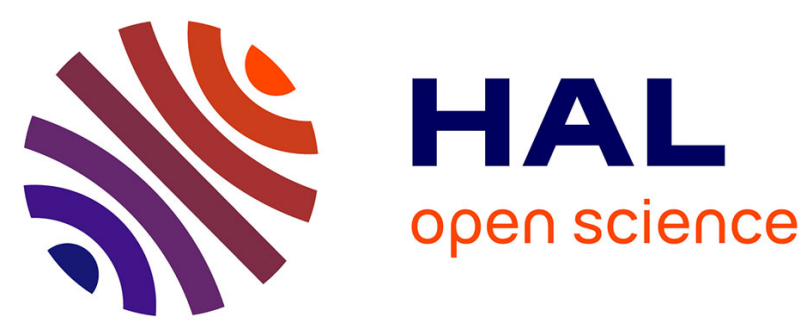

\title{
Self-organization of complete organic monolayers via sequential post-deposition annealing
}

Stefano Chiodini, Gabriele D'avino, Luca Muccioli, Luca Bartolini, Denis Gentili, Stefano Toffanin, Cristiano Albonetti

\section{- To cite this version:}

Stefano Chiodini, Gabriele D'avino, Luca Muccioli, Luca Bartolini, Denis Gentili, et al.. Selforganization of complete organic monolayers via sequential post-deposition annealing. Progress in Organic Coatings, 2020, 138, pp.105408. 10.1016/j.porgcoat.2019.105408 . hal-02399114

\section{HAL Id: hal-02399114 https://hal.science/hal-02399114}

Submitted on 15 Dec 2019

HAL is a multi-disciplinary open access archive for the deposit and dissemination of scientific research documents, whether they are published or not. The documents may come from teaching and research institutions in France or abroad, or from public or private research centers.
L'archive ouverte pluridisciplinaire HAL, est destinée au dépôt et à la diffusion de documents scientifiques de niveau recherche, publiés ou non, émanant des établissements d'enseignement et de recherche français ou étrangers, des laboratoires publics ou privés. 


\title{
Self-organization of complete organic monolayers via sequential post-deposition annealing
}

\author{
Stefano Chiodini ${ }^{1,2}$, Gabriele D’Avino ${ }^{3}$, Luca Muccioli ${ }^{4,5}$, Luca Bartolini ${ }^{1,6}$, Denis Gentili ${ }^{1}$, \\ Stefano Toffanin ${ }^{1}$ and Cristiano Albonetti ${ }^{1 *}$ \\ ${ }^{1}$ Consiglio Nazionale delle Ricerche - Istituto per lo Studio dei Materiali Nanostrutturati (CNR-ISMN), Via \\ P. Gobetti 101, 40129 Bologna, Italy. \\ ${ }^{2}$ Departamento de Química Física, Universidad de Zaragoza, Campus Plaza San Francisco, 50009 Zaragoza, \\ Spain \\ ${ }^{3}$ Institut Néel, CNRS and Grenoble Alpes University, 38042 Grenoble, France. \\ ${ }^{4}$ Department of Industrial Chemistry "Toso Montanari", University of Bologna, Viale Risorgimento 4, 40136 \\ Bologna, Italy \\ ${ }^{5}$ Institut des Sciences Moléculaires, UMR 5255, University of Bordeaux, 33405 Talence, France. \\ ${ }^{6}$ Department of Chemistry “G. Ciamician”, University of Bologna, Via F. Selmi 2, 40126 Bologna, Italy;
}

Corresponding author: cristiano.albonetti@enr.it 


\begin{abstract}
Organic molecular beam deposition has been used to surpass the chemical approach commonly adopted for coating $\mathrm{SiO}_{\mathrm{x}}$ surfaces, obtaining a smooth and uniform monomolecular layer of sexithiophene that fully covers the $\mathrm{SiO}_{\mathrm{x}}$ surface on the centimetre length scale. This result has been achieved by submitting sexithiophene sub-monolayer films grown at different substrate temperatures to a post-deposition annealing process. Through Scanning Probe Microscopy techniques, morphological, tribological and mechanical measurements have highlighted the existence of face-on molecular aggregates on the $\mathrm{SiO}_{\mathrm{x}}$ surface and their re-organization by means of a post-annealing process. Atomistic molecular dynamics simulations complement experimental observations, shedding light on the microscopic aspects of molecular diffusion and aggregates reorganization. Exploiting the molecular reorganization upon post-annealing, almost perfect 6T monolayers were grown through a sequence of deposition and annealing steps. This preparation technique represents a new route for changing surface properties by using high controlled monomolecular layers.
\end{abstract}

\title{
Keywords
}

Scanning Probe Microscopy, Organic Growth, $\alpha$-Sexithiophene, Face-on Molecules, Annealing, Molecular Dynamics simulations 


\section{Introduction}

Surface engineering of solid substrates enables to design and develop functional materials with specific and tailorable physical, chemical or biological properties, such as wettability, friction, adhesion, surface energy, reactivity and biocompatibility [1]. Surface functionalization has found applications in a wide range of research areas, like thin-film technology, nanotechnology, electronics, (bio)sensors, bioactive and self-cleaning surfaces, cell adhesion and protein resistant surfaces [2-5]. On the other hand, manufacturing research has exploited surface functionalization to develop protective coatings, enabling materials to resist properly in specific working conditions.

The modification of surfaces is accomplished by depositing either monomolecular adlayer or thicker films. Spin-coating is the commonly used technique to deposit films of soluble molecules with thickness ranging from a few tens of nanometers to microns, while surface functionalization by means of self-assembled monolayers (SAMs), LangmuirBlodgett films and molecular grafting with irreversible chemical bonds is the most prominent strategies to form ordered monolayers of molecules [6]. In particular, grafting of silanes has been largely used to form covalently attached monolayers on both thermal $\left(\mathrm{SiO}_{2}\right)$ and native silicon $\left(\mathrm{SiO}_{\mathrm{x}}\right)$ oxide surfaces, and on glasses [7]. These systems are relatively robust from a physical and chemical point of view, but they lack in surface coverage homogeneity and thickness uniformity [6].

Ultra-thin films made of physically adsorbed organic small molecules can be a valid alternative for engineering both $\mathrm{SiO}_{2}$ and $\mathrm{SiO}_{\mathrm{x}}$ surfaces [8]. Their low molecular weight allows sublimating them in Ultra-High Vacuum (UHV), forming thus ultra-thin films in a high controlled fashion down to the molecular scale [9]. Such films have well-defined molecular conformation and organization [10-12], crystallinity [13], grain size [14,15] and orientation [16].

The organic film morphology at the $\mathrm{SiO}_{2}$ interface (where the silicon oxide is used as dielectric substrate) has been deeply investigated for optimizing the electrical performances of organic electronics devices [17]. These endeavours have shown that morphological properties of the first few monolayers (at most three) are correlated to the conduction properties of devices [18-20]. 
Amongst molecules sublimed in UHV, rod-like ones have shown a reproducible route of film growth when deposited on the chemically inert and flat $\mathrm{SiO}_{2}\left(\right.$ or $\mathrm{SiO}_{\mathrm{x}}$ ) surface [21]. First, molecules form stable nuclei that evolve as islands during the deposition (submonolayer regime), until coalescing (coalescence and percolation regimes) to form a continuous organic layer [22]. The sub-monolayer regime is characterized by the coexistence of two molecular configurations: the edge-on configuration, in which the molecule backbone is nearly orthogonal to the surface (islands), and the face-on configuration where the backbone is parallel to the surface [23]. Aggregates of face-on molecules were observed in sub-monolayer films of sexithiophene (6T) by photoluminescence spectroscopy (PL) [24] and X-ray diffraction [25], while a molecular wetting layer on the $\mathrm{SiO}_{2}$ surface was inferred by Thermal Desorption Spectroscopy for Indigo [26] and predicted by molecular dynamics simulations for pentacene [27]. Molecular dynamics simulations have also predicted clusters of face-on molecules of pentacene on $\mathrm{SiO}_{2}$ [28] and fullerene [29]. PL and Ultrasonic Force Microscopy (UFM) have provided useful insights on the initial growth stages of organic films, by imaging 6T $J$-aggregates formed on $\mathrm{SiO}_{2}$ both optically and mechanically [30,31]. Later on, PL investigations were extended to chemically treated $\mathrm{SiO}_{x}$ and $\mathrm{SiO}_{2}$ for correlating the formation of face-on aggregates to the physical/chemical properties of the surface [32]. These results, combined to UFM imaging [31], suggest two different configurations of 6T face-on aggregates linked to the surface hydrophilicity: on $\mathrm{SiO}_{2}$, that is less hydrophilic than $\mathrm{SiO}_{\mathrm{x}}$, molecular mounds with PL signal were formed [31] whereas on $\mathrm{SiO}_{\mathrm{x}}$ a wetting layer without PL signal could be promoted as possible molecular configuration [32].

To the best of our knowledge, successful attempts to re-organize such face-on aggregates have been not reported in the literature. This manuscript aims at showing how a complete 6T monolayer can be realized by post-deposition processing [33], by implementing sequential post-deposition annealing of face-on aggregates.

\section{Experimental and Methodological Section}

\subsection{Organic Molecular Beam Deposition}

Sexithiophene was purchased in powder from Sigma Aldrich ${ }^{\circledR}$ and deposited on $\mathrm{Si}$ substrates ( $p$-type, $\rho=2-10 \Omega \mathrm{cm}$ ) coated with native $\mathrm{SiO}_{\mathrm{x}}$ by using an Organic Molecular 
Beam Deposition (OMBD) system with a base pressure of $2 \cdot 10^{-8} \mathrm{mBar}$. A Quartz MicroBalance (QMB), placed close to the substrate, was used to monitor the weight of molecules (with 1ng of sensitivity) adsorbed on the substrate. To avoid thermal drift effects on measurements, $\mathrm{QMB}$ was kept at $20^{\circ} \mathrm{C}$ by means of a water cooler. Sub-monolayer $6 \mathrm{~T}$ films were grown by depositing a fixed amount of molecules ( $50 \mathrm{ng}$, as previously reported in the literature [34]) with constant impinging flux $F$ of $(4 \pm 1) \mathrm{ng} / \mathrm{min}$. Sub-monolayer films were grown with increasing substrate temperature $\left(T_{S}=25,52,80,100\right.$ and $\left.120^{\circ} \mathrm{C}\right)$. For every temperature $T_{S}$, two post-deposition annealing times were tested, i.e. 30 minutes and 1 hour. According to experimental results [34], 6T monolayers were grown by depositing $150 \mathrm{ng}$ at $T_{S}=80,100{ }^{\circ} \mathrm{C}$ via a sequence of three $50 \mathrm{ng}$ depositions, spaced out by two post-deposition annealing 1 hour-long. During each annealing step, sample and Knudsen cell shutters were closed, and the cell temperature was decreased to $180^{\circ} \mathrm{C}$ for preventing undesired molecular deposition [35]. After the last deposition, the substrate was cooled to $25^{\circ} \mathrm{C}$ (approx. 10 minutes), and exposed to air.

\subsection{Scanning Probe Microscopies characterizations of organic films}

Topographic Atomic Force Microscopy (AFM) images of 6T sub-monolayer and monolayer films, collected in Intermittent Contact Mode (ICM) and Contact Mode (CM), were used for investigating the films morphology $v_{S} T_{S}$ and post-deposition annealing.

Standard morphological parameters where used to describe the evolution of 6T submonolayer films [36], except the interstitial space $\ell$ between 6T islands, for which a statistical method was employed. By definition, $\ell$ is the difference between the inter-island centroid distance $r_{c}$ and twice the island equivalent disk radius $r_{e}$, i.e. $\ell=r_{c}-2 \cdot r_{e}$ (see inset of Figure 2). The former is calculated as two times the position of the first zero crossing of the radial autocorrelation function $\boldsymbol{G}(r)$ [37], while the latter is the average radius of the disc with the same projected area as the islands [38]. All morphological parameters reported in the manuscript are the average of values measured on three topographic images collected in three different surface regions (image sizes: $20 \mu \mathrm{m} \times 20 \mu \mathrm{m}$ and $10 \mu \mathrm{m} \times 10$ $\mu \mathrm{m})$.

Height measurements were statistically measured on $2 \mu \mathrm{m} \times 2 \mu \mathrm{m}$ images. The height of 6T islands $h$ was calculated as the difference between the peak centres of the 
height distributions (with the absolute error calculated by the sum of peak standard deviations) [39].

Mechanical and tribological properties of the face-on molecular aggregates were observed with three SPM techniques: (a) ICM and UFM where used for investigating their stiffness, while (b) Lateral Force Microscopy (LFM) was employed to evaluate the surface friction.

ICM in amplitude modulation was used to image topographically $6 \mathrm{~T}$ films and, through phase imaging, to evaluate their stiffness. In general, this technique is able to exert very low forces when the tip-sample interaction is properly set [40]. The averaged tipsample force $\left(F_{t s}\right)$ is relatively low for high amplitude set-point $A_{S P}$, i.e. corresponding to a small reduction of the free oscillation amplitude of the cantilever $A_{0}$ (namely in the attractive regime), while it becomes relatively high for low $A_{S P}$, i.e. in a high reduction of $A_{0}$ (namely repulsive regime) [41,42]. $F_{t s}$ was calculated by using the relationship reported by García et al [41] with the cantilever elastic constant $k$ evaluated through the Sader method [43]. Several types of silicon cantilevers were employed in ICM measurements: MikroMash NSC35 (resonant frequency $\omega_{0}$ of $\sim 200$ and $\sim 300 \mathrm{kHz}$, spring constant $k$ of $\sim 11$ and $\sim 22 \mathrm{~N} / \mathrm{m}$,), NT-MDT NSG10 (resonant frequency $\omega_{0}$ of $\sim 240 \mathrm{kHz}, k$ ranging from $\sim 11$ to $\sim 17 \mathrm{~N} / \mathrm{m})$ and Nanosensors PPP-NCH $\left(\omega_{0} \sim 300 \mathrm{kHz}, k \sim 16 \mathrm{~N} / \mathrm{m}\right)$. Accordingly, $F_{t s}$ has ranged from 0.13 to $1.75 \mathrm{nN}$ in attractive regime and from 0.20 to $2.55 \mathrm{nN}$ in the repulsive one.

Simultaneously to the topographic image, the phase image was recorded for keeping the tip-sample interaction in attractive or repulsive regime along the whole image [41]. Out of the tip-sample interaction, the phase $\phi$ of the free cantilever oscillations is $90^{\circ}$, in delay with respect to the sinusoidal signal that drives the cantilever oscillation. When the tip interacts with the surface, the cantilever dissipates part of its energy through nonconservative tip-sample interactions, and a phase lag $\Delta \phi$ in the cantilever oscillations occurs [44]. The phase $\phi$ in interactions will be $90^{\circ}+\Delta \phi$ with $\phi>90^{\circ}$ in attractive regime and $\phi<90^{\circ}$ in repulsive regime (as ruled by Cleveland et al [44]). In the repulsive regime, the tip indents the surface and the overall derivative forces exercised by the tip to the sample can be approximated to the local sample stiffness $\langle S\rangle$ [45]. Assuming a force derivative (or stiffness) very small in magnitude compared with $k$ [46], an approximation 
which holds true in our case, the phase lag $\Delta \phi$ is related to the local stiffness $\langle S\rangle$ through the relationship:

$$
\langle S\rangle=\frac{k}{Q} \Delta \phi
$$

Eq. (1) shows that phase imaging provides a map of stiffness variation on the sample surface such that a stiffer region has larger $\Delta \phi$.

LFM measurements were employed to investigate the surface friction of the substrate upon the molecular re-organization promoted by post-deposition annealing. LFM has been extensively used to study friction of various samples with ultralow loads (few $\mathrm{nN}$ ) and scan range from tens of micrometres down to the atomic scales [47]. In general, it is a contact technique where the tip exercises a normal force $F_{N}$ on the surface (i.e. it works in repulsive regime) and, simultaneously, it experiences a lateral force $F_{L}$ generated by surface friction. Along the surface scan, the cantilever deflection is kept constant for imaging the surface topography (constant $F_{N}$ ) whereas cantilever torsions induced by lateral forces $\left(F_{L}\right)$ are recorded for imaging the surface friction (for a sketch of LFM operations see Supporting Information -SI-). In order to remove topography-induced features, retrace (backward scan) torsions were subtracted to trace (forward scan) ones (difference image) [48]. Accordingly, the difference image shows only material-induced surface friction [49], mapping how the friction coefficient $\mu$, a dimensionless scalar value describing the ratio between the lateral force $F_{L}$ and the normal force $F_{N}$, changes on the surface (see SI). For LFM measurements were used $\mathrm{Si}_{3} \mathrm{Ni}_{4}$ cantilevers for soft contact mode from BudgetSensors $(k \sim 0.02 \mathrm{~N} / \mathrm{m}$ and $k \sim 0.06 \mathrm{~N} / \mathrm{m}$ for the long and the short cantilever, respectively).

UFM is based on a standard AFM system operating in CM to which an additional ultrasonic vibration is imposed to the sample [50]. Specifically, the sample holder is composed of a piezoelectric disk, attached to a metal disk to which the sample is glued via a thin layer of ultrasonically transparent and replaceable binder, namely phenylsalicilate. The ultrasonic vibrations applied ( 2 MHz) are well above the resonance frequency of CM cantilevers (tens of $\mathrm{kHz}$ ); hence the cantilever is not be able to linearly follow the surface vibration because of its inertia [50]. If the ultrasonic excitation amplitude is sufficiently high, the tip-sample distance is modulated within the nonlinear tip-sample force interaction 
regime and the cantilever experiences of an additional static force [51]. This static force causes an additional deflection to the cantilever (UFM signal) with a magnitude that depends on the details of the tip-sample interaction force, i.e. on material properties such as elasticity and adhesion [52,53]. In this way, surface nanoscale elastic discontinuities (like stiffness variations) can be easily detected. The cantilevers employed for UFM experiments were Bruker MPP $\left(\omega_{0} \sim 20\right.$ and $\sim 75 \mathrm{kHz}, k$ of $\sim 0.9$ and $\left.\sim 3 \mathrm{~N} / \mathrm{m}\right)$.

All SPM experiments were performed with SOLVER HV-MFM (NT-MDT, Zelenograd, Moscow, RU) and Explorer (Bruker, Coventry, UK) AFM microscopes, used for ICM/LFM and UFM measurements, respectively.

\subsection{Molecular simulation details}

A slab model of amorphous silica with surface vectors measuring about $15 \mathrm{~nm} \times$ $15 \mathrm{~nm}$ and a thickness of $5 \mathrm{~nm}$ ( $23600 \mathrm{SiO}_{2}$ formula units) was prepared according to the procedure described in reference [54]. Amorphous silica interactions were described with the Clay force field [55], while the generalized AMBER force field [56] already tested in previous works [57] was adopted for 6T; standard Lorentz-Berthelot mixing rules were employed to describe the organic-inorganic interaction, and the particle mesh Ewald method was employed for the evaluation of electrostatic interactions. In all simulation series we employed periodic boundary conditions in three dimensions, with a box size of $40 \mathrm{~nm}$ in the direction normal to the surface to effectively decouple periodic replica along that direction. Only the uppermost nanometer of silica atoms was allowed to move, with the remaining $4 \mathrm{~nm}$ being fixed at their initial positions. Simulations were carried out with NAMD [58], NVT conditions maintained with a velocity scaling thermostat.

Three types of simulations were performed, labelled "SA", "SB", "SC". In the first (SA), half of the silica surface was covered by a preformed terrace of crystalline $6 \mathrm{~T}$. The terrace was created by replicating the 6 T bulk HT crystal structure [59] $(12 \times 39 \times 1$ supercell, 468 molecules) and presents a step edge normal to the crystal axis $a$. The terrace was equilibrated at $27^{\circ} \mathrm{C}$ for $2 \mathrm{~ns}$ before introducing 24 face-on $6 \mathrm{~T}$ molecules in the remaining half surface. After thermalizing the system for a $2 \mathrm{~ns}$, its time evolution was followed for 40ns at the temperatures of $27^{\circ} \mathrm{C}$ and $127^{\circ} \mathrm{C}$.

In a second combination of simulations (SB), to reproduce the formation of mounds, $3006 \mathrm{~T}$ molecules were deposited, one every $1 \mathrm{~ns}$, at $227^{\circ} \mathrm{C}$, according to the 
computational procedure described in reference [60]. Differently from the case of the deposition of $6 \mathrm{~T}$ on fullerene [60], the formation of crystalline islands was not observed during the deposition; only aggregates of face-on molecules, mostly parallel among them, were found. Then, to imitate the post-deposition annealing process, the deposition was stopped, the temperature set to $80^{\circ} \mathrm{C}$, and a new simulation was carried out for $10 \mathrm{~ns}$. After this simulation, all the molecules that had diffused from their original position to a position outside the simulation box (calculated without applying periodic boundary conditions to their trajectory), were removed, and a new simulation was started. The procedure was iterated seven times, leading to the removal of 60 molecules in $70 \mathrm{~ns}$.

In a third set of simulations (SC), 80 face-on $6 \mathrm{~T}$ molecules were placed on top of the silica surface, resulting in a coverage of one molecule every $2.9 \mathrm{~nm}^{2}$. The system was equilibrated for $10 \mathrm{~ns}$ at increasing temperatures $\left(27,77,127,177,227,277{ }^{\circ} \mathrm{C}\right)$, before running further $60 \mathrm{~ns}$ used for the analysis of the diffusion behavior.

\section{Results and Discussions}

\subsection{Morphological evolution of 6T sub-monolayer films vs temperature}

Figure 1 shows the morphological evolution of $6 \mathrm{~T}$ sub-monolayer films $v s$ the substrate temperature $T_{S}$. At $25^{\circ} \mathrm{C}$ (Figure 1a), $6 \mathrm{~T}$ films are composed of islands with small area $\bar{A}$, and relatively high surface density $N$ (islands per unit area, i.e. $\# / \mu \mathrm{m}^{2}$ ) and surface coverage $\theta$ (Table 1). Islands show dendritic shape $[61,62]$ with fractal dimension $D_{f}$ of (1.67 \pm 0.04$)$, value which agrees well with the expected dimension for classical diffusionlimited aggregation (DLA) [63]. As the temperature $T_{S}$ increases (Figure b-e), $N$ decreases because of the molecular diffusion is increased [64-66]. As shown by Venables and coworkers [67], this scenario corresponds to the initially incomplete condensation regime, in which nucleated clusters capture molecules by surface diffusion even if desorption is involved in the process [64]. The density of stable islands $N$ is expected to vary as an activated Arrhenius law with the substrate temperature $T_{S}$ :

$$
N \propto \exp \left(-\frac{E_{N}}{k_{B} T_{S}}\right)
$$

where $E_{N}$ is the activation energy for island formation. The log-lin plot of the data shows a linear behaviour for $T_{S}<120^{\circ} \mathrm{C}$, yielding an activation energy of $(600 \pm 10) \mathrm{meV}$ 
by linear regression. Films grown at $120^{\circ} \mathrm{C}$ were not included in the regression because, within the Venables scenario [67], they are instead in the totally incomplete condensation regime, which is characterized by few islands (over large area), randomly distributed in position, size and shape (Figure 1e) [68].

Unlike $N$, the surface coverage $\theta$ is rather insensitive to $T_{S}$. It decreases only few percentage from $25^{\circ} \mathrm{C}(\sim 38 \%)$ to $52^{\circ} \mathrm{C}(\sim 31 \%)$ due to re-evaporation processes [64], after that it remains constant to $\sim 33 \%$ up to $100^{\circ} \mathrm{C}$. Eventually, at $120^{\circ} \mathrm{C}$ coverage falls down to $\sim 2 \%$ where re-evaporation drastically affects the film growth [64]. Since the number of islands decreases with temperature in the range where $\theta$ is constant $\left(25-100^{\circ} \mathrm{C}\right)$, the average area $\bar{A}$ increases accordingly.

\begin{tabular}{|c|c|c|c|c|}
\hline $\begin{array}{c}T_{S} \\
{\left[{ }^{\circ} \mathrm{C}\right]}\end{array}$ & $\begin{array}{c}\bar{A} \\
{\left[\cdot 10^{-2} \mu \mathrm{m}^{2}\right]}\end{array}$ & $\begin{array}{c}N \\
{\left[\# / \mu \mathrm{m}^{2}\right]}\end{array}$ & $\begin{array}{c}\theta \\
{[\%]}\end{array}$ & $D_{f}$ \\
\hline 25 & $(5 \pm 1)$ & $(6.1 \pm 0.5)$ & $(38 \pm 2)$ & $(1.67 \pm 0.04)$ \\
\hline 52 & $(26 \pm 9)$ & $(8.3 \pm 0.8) \cdot 10^{-1}$ & $(31 \pm 2)$ & $(1.68 \pm 0.10)$ \\
\hline 80 & $(180 \pm 60)$ & $(1.8 \pm 0.2) \cdot 10^{-1}$ & $(33 \pm 1)$ & $(1.31 \pm 0.09)$ \\
\hline 100 & $(440 \pm 80)$ & $(5.2 \pm 0.9) \cdot 10^{-2}$ & $(34 \pm 1)$ & $(1.44 \pm 0.05)$ \\
\hline 120 & $(300 \pm 70)$ & $(7 \pm 1) \cdot 10^{-3}$ & $(2 \pm 1)$ & $/$ \\
\hline
\end{tabular}

Table 1. Morphological descriptors of 6T islands (average area $\bar{A}$, islands per unit area $N$, surface coverage $\theta$ and fractal dimension $\left.D_{f}\right) v s$ substrate temperatures $T_{S}$. Fractal dimension at $120^{\circ} \mathrm{C}$ was not calculated because islands are few (statistically not relevant) and the growth of film is in the totally incomplete condensation regime, as describe in ref. [67].

As indicated by fractal dimension values in Table 1 , above $52{ }^{\circ} \mathrm{C}$ the island shape exhibits a transition from dendritic (Figure 1a,b - in average $D_{f} \sim 1.68-$ ) to compact (Figure 1c,d - in average $D_{f} \sim 1.37-$ ). A relevant example of this transition is reported in the literature [69]: at low temperatures, the edge diffusion rate of molecules is very low, and the islands are ramified (Fractal islands, $D_{f} \rightarrow 2$ ) [62], while at high temperatures, the islands grow while maintaining a compact structure (Compact islands, $D_{f} \rightarrow 1$ ). 

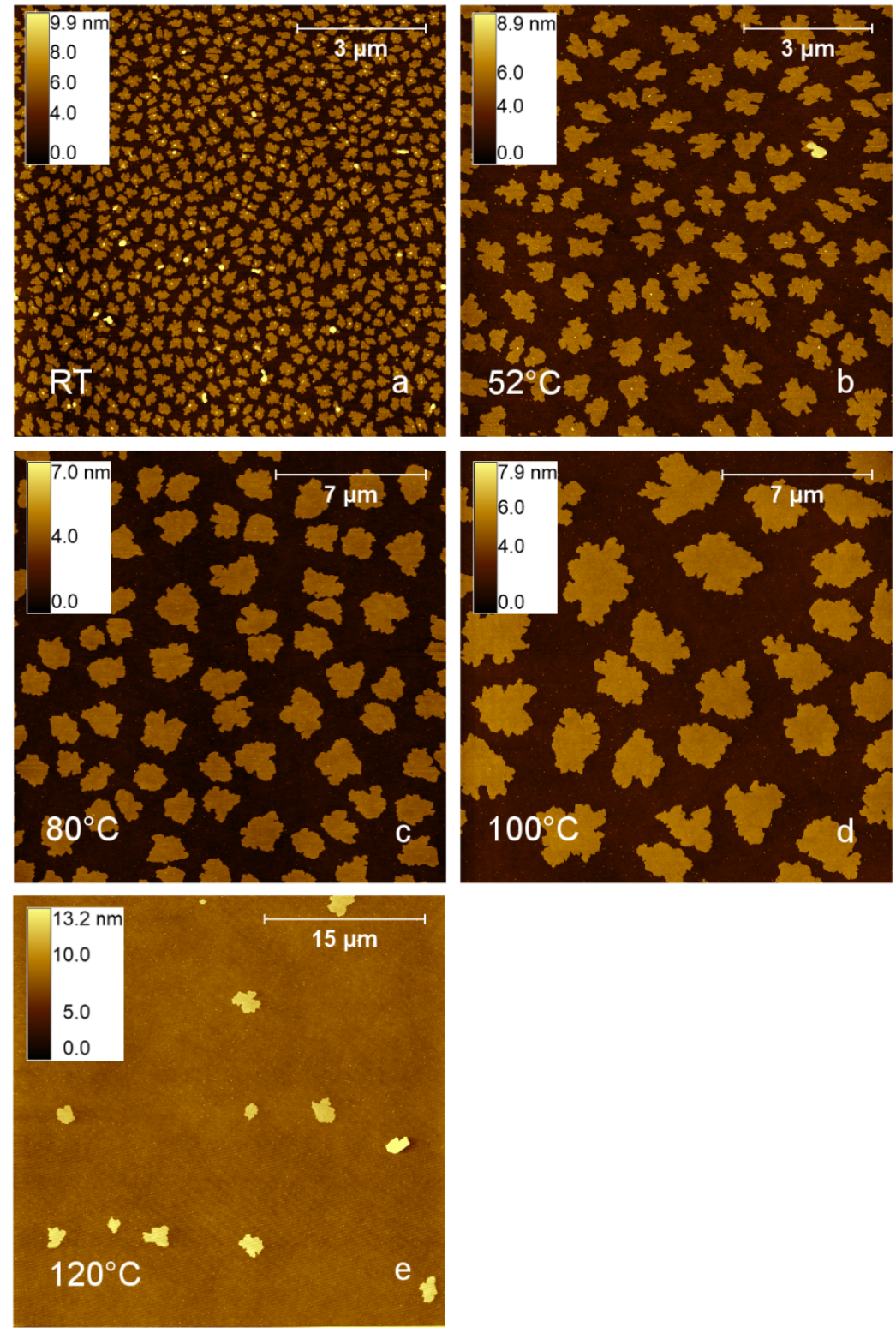

Figure 1. AFM topographic images of sub-monolayer films grown on native $\mathrm{SiO}_{\mathrm{x}}$ substrates at different temperatures (50 ng of $6 \mathrm{~T}$ molecules). (a) $25^{\circ} \mathrm{C}$, the scan area is $10 \mu \mathrm{m} \times 10 \mu \mathrm{m}$ for stressing the high $N$ of islands; (b) $52{ }^{\circ} \mathrm{C}$, the scan area is $10 \mu \mathrm{m} \times 10 \mu \mathrm{m}$ to show how the average $\bar{A}$ increases; (c) $80{ }^{\circ} \mathrm{C}, 20 \mu \mathrm{m} \times$ $20 \mu \mathrm{m}$; (d) $100^{\circ} \mathrm{C}, 20 \mu \mathrm{m} \times 20 \mu \mathrm{m}$; (e) $120^{\circ} \mathrm{C}, 40 \mu \mathrm{m} \times 40 \mu \mathrm{m}$. The evolution of island morphology agrees with the diffusion-limited aggregation growth model, for which dendritic islands are formed at low substrate temperature, whereas compact islands are formed at high substrate temperature.

\subsection{Influence of annealing on $6 \mathrm{~T}$ sub-monolayer films}

Length-scales of topographic images do not offer a direct proof of the aforementioned conjecture, i.e. sub-monolayer films could actually consist of two regions 
both coated by $6 \mathrm{~T}$ molecules. The interstitial areas between islands, where molecules lie down with the long molecular axis parallel to the native $\mathrm{SiO}_{\mathrm{x}}$ substrate - namely aggregates of face-on molecules - and the islands in which molecules are perpendicular to the substrate (edge-on molecules) [24,70].

\begin{tabular}{|c|c|c|c|c|c|}
\hline $\begin{array}{c}T_{S} \\
{\left[{ }^{\circ} \mathrm{C}\right]}\end{array}$ & $\begin{array}{c}\bar{A} \\
{\left[\cdot 10^{-2} \mu \mathrm{m}^{2}\right]}\end{array}$ & $\begin{array}{c}N \\
{\left[\# / \mu \mathrm{m}^{2}\right]}\end{array}$ & $\begin{array}{c}\theta \\
{[\%]}\end{array}$ & $\begin{array}{c}D_{f} \\
{[\mu \mathrm{m}]}\end{array}$ \\
\hline 80 & $(180 \pm 60)$ & $(1.8 \pm 0.2) \cdot 10^{-1}$ & $(33 \pm 1)$ & $(1.31 \pm 0.09)$ & $(1.1 \pm 0.1)$ \\
\hline 100 & $(440 \pm 80)$ & $(5.2 \pm 0.9) \cdot 10^{-2}$ & $(34 \pm 1)$ & $(1.44 \pm 0.05)$ & $(2.7 \pm 0.2)$ \\
\hline $80+\mathrm{A}$ & $(400 \pm 100)$ & $(0.6 \pm 0.2) \cdot 10^{-1}$ & $(35 \pm 2)$ & $(1.6 \pm 0.1)$ & $(2.6 \pm 0.2)$ \\
\hline $100+\mathrm{A}$ & $(700 \pm 100)$ & $(4 \pm 1) \cdot 10^{-2}$ & $(34 \pm 2)$ & $(1.70 \pm 0.08)$ & $(2.1 \pm 0.3)$ \\
\hline
\end{tabular}

Table 2. Morphological descriptors of 6T islands (average area $\bar{A}$, islands per unit area $N$, surface coverage $\theta$, fractal dimension $D_{f}$ and average length between islands $\ell$ ) without and with post-deposition annealing of one hour at 80 and $100{ }^{\circ} \mathrm{C}$.

By assuming that molecular diffusion of molecules could continue even after the deposition process, their reorganization can be promoted by annealing the substrate. To test this hypothesis, 1 hour of annealing time was used for samples grown at 80 and 100 ${ }^{\circ} \mathrm{C}$ (from here termed $80+\mathrm{A}$ and $100+\mathrm{A}$, see Figure 2 ) . After annealing, the surface

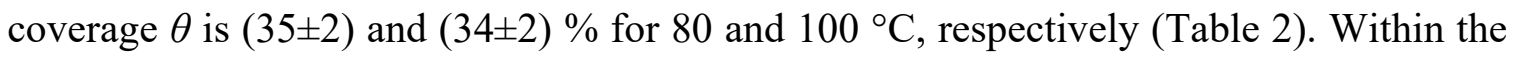
experimental errors, these values are equal to the ones reported for sample not annealed (Table 2, 80 and 100 values), suggesting a negligible molecular re-evaporation during extra time. Conversely, annealing affects both the average area $\bar{A}$ and the islands surface density $N$. For both $T_{S}\left(80\right.$ and $\left.100^{\circ} \mathrm{C}\right), \bar{A}$ doubles while $N$ decreases The linear regression for calculating the activation energy using Eq. 2 was done on data from samples $25^{\circ} \mathrm{C}, 52^{\circ} \mathrm{C}$, $80+\mathrm{A}, 100+\mathrm{A}$ (see footnote). The sample deposited at $120^{\circ} \mathrm{C}$ isn't considered in the linear regression because of films are in another condensation regime and it results morphologically stable, i.e. unaffected by annealing, even after over 2 hours in vacuum [71]. The decrease of $N$ corresponds to an apparent increased activation energy for nucleation $E_{N A}$, from $E_{N}=(600 \pm 10) \mathrm{meV}$ without annealing to $E_{N A}=(650 \pm 20) \mathrm{meV}$ (see

\footnotetext{
${ }^{\text {a }}$ Negligible re-organization effects were observed for 25 and $52{ }^{\circ} \mathrm{C}$, as well as for extra time shorter than 1 h (i.e. 30 minutes). Accordingly, 25 and $52^{\circ} \mathrm{C}$ correspond to $25+\mathrm{A}$ and $52+\mathrm{A}$, i.e. they are unaffected by annealing.
} 
SI). Similarly to Ag thin films [72], this difference can be attributed to surface diffusion as the key mass transport mechanism responsible to the island changes.
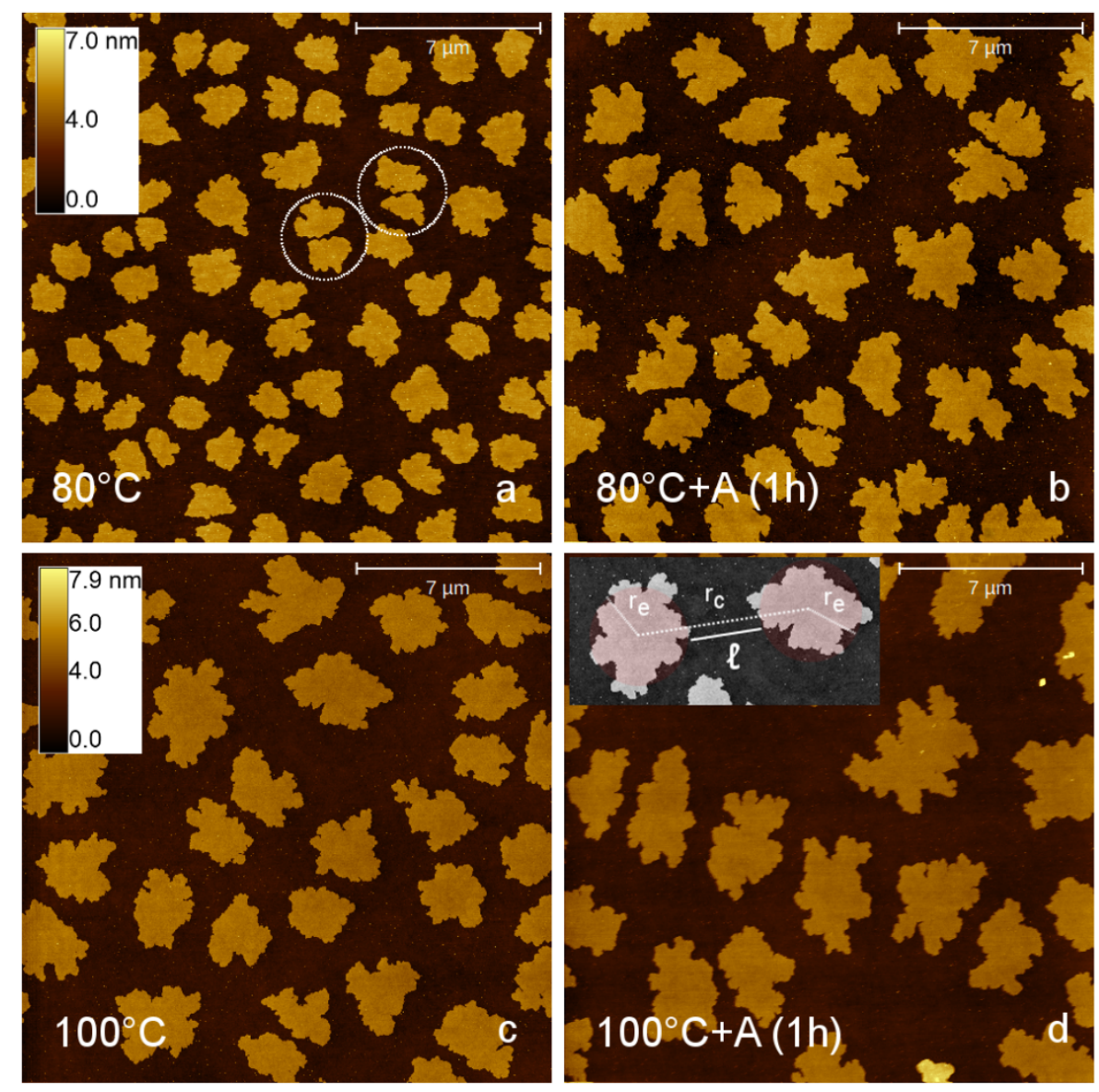

Figure 2. AFM topographic images of $6 \mathrm{~T}$ sub-monolayer films after deposition - (a) at $80{ }^{\circ} \mathrm{C}$ and (c) at 100 ${ }^{\circ} \mathrm{C}$ - and after annealing process - (b) 1 hour of annealing time at $80{ }^{\circ} \mathrm{C}$ and (d) 1 hour of annealing time at $100{ }^{\circ} \mathrm{C}$. All images are $20 \mu \mathrm{m} \times 20 \mu \mathrm{m}$. (b) and (d) panels have the same $z$-scale of (a) and (c) panels, respectively. They are not reported for graphical purposes. Inset: Scheme of the mathematical method used to measure statistically the interstitial space between islands $\ell$. The islands centroids distance is $r_{c}$ whereas $r_{e}$ is the islands equivalent disk radius - red circles - (see Method Section).

In particular, since island mobility is null at the measured coverages $(\theta>10-15 \%)$ $[73,74]$ a re-organization process of face-on molecules should be responsible for the morphological changes of islands. Thanks to the additional time and the extra kinetic energy provided by $T_{S}$ along annealing time, face-on molecules diffuse on the surface and, finally, are incorporated in the islands. Consequently, interstitial areas become progressively smaller as long as two or more islands can coalesce and form a larger one (static coalescence). In this framework, the shorter is the average length $\ell$ between islands 
(see inset of Figure 2d), the larger is the probability of molecules to be re-organized. For the $80{ }^{\circ} \mathrm{C}$ sample, annealing increases $\ell$ from $(1.1 \pm 0.1)$ to $(2.6 \pm 0.2) \mu \mathrm{m}$, suggesting a static coalescence of neighbouring islands where $\ell<1.1 \mu \mathrm{m}$ (some examples of possible coalescing islands are circled in Figure 2a). The increase of $\ell$ corresponds to both larger islands and smaller surface density $N$. At $100^{\circ} \mathrm{C}, \ell$ slightly decreases from $(2.7 \pm 0.2)$ to $(2.1 \pm 0.3) \mu \mathrm{m}$ due to annealing, thus $N$ (Figures $2 \mathrm{c}$ and $2 \mathrm{~d}$ ).

Annealing also influences islands contours promoting their ramification, i.e. dendritic shapes (Figure 2b, 2d and Table 2). Accordingly, the fractal dimension $D_{f}$ increases at both annealing temperatures (cf. Table 2). As reported in the literature, annealing can prompt a strain-driven instability of islands due to the surface stress distinction between islands and substrate [75], leading to some unusual growth phenomena of islands like ramification [76]. This scenario was labelled both post-(deposition)growth and post-nucleation [33].

The analysis of height distributions concludes the morphological investigation of 6T sub-monolayer films grown with (or without) post-deposition annealing (Figure $3-25$ ${ }^{\circ} \mathrm{C}$ samples were used as height reference) [14]. In order to obtain reliable height measurements, the height sensitivity in ICM was estimated to $0.5 \AA$ from microscopy noise $^{\mathrm{b}}$, and the tip-sample interaction was carefully controlled to avoid both image artefacts induced by $A_{0}<10 \mathrm{~nm}$ [77] (all measurements were done with $A_{0}>12 \mathrm{~nm}$ ) and interaction instabilities [78].

As shown in Figure 3a, height distributions show two sharp Gaussian peaks centred at low (close to $0.5 \mathrm{~nm}$ ) and high (scattered around $4 \mathrm{~nm}$ ) height values, corresponding to the substrate and 6T islands, respectively. They were extracted from $1 \mu \mathrm{m} \times 1 \mu \mathrm{m}$ topographic images with variable surface coverage of $6 \mathrm{~T}$ islands (not shown), so the

\footnotetext{
${ }^{\mathrm{b}}$ The height sensitivity is defined as the minimum piezo displacement along z-direction detected from the microscope. By taking inspiration from interferometric measurements [97], the system noise was measured from stationary scans by repeatedly taking data at same location without moving any part. In this way, electrical and mechanical noise are considered as a whole. Experimentally, the height was recorded in time for a stationary tip (without scanning the surface) interacting with a $\mathrm{SiO}_{\mathrm{x}}$ surface. The signal RMS is the height sensitivity. By repeating the procedure for all cantilevers used in ICM measurements, the height sensitivity was estimated to $0.5 \AA$. The thermal noise of free cantilever is an additional source of noise. It depends on the cantilever elastic constant $k$ [98] and, for the cantilevers used in ICM experiments, was calculated to be about $0.2 \AA$, which is included in the system noise.
} 
integrated peak areas, either for substrate (ranging from 20 to $50 \%$ ) or $6 \mathrm{~T}$ islands (80 to $50 \%$ ), reflect such variations.
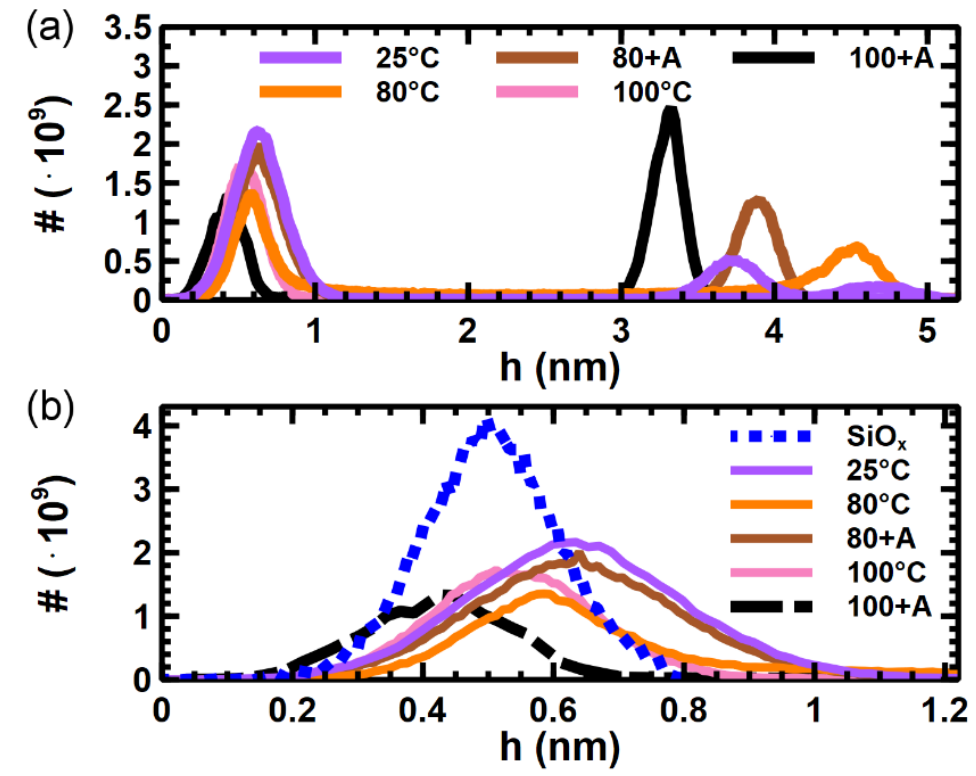

(c)
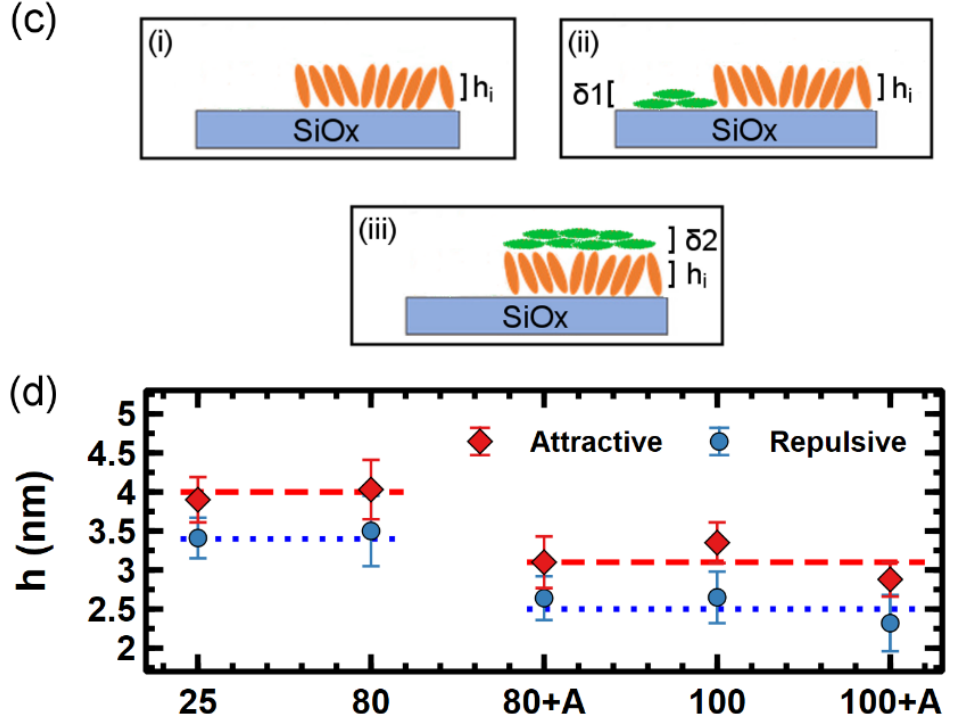

Figure 3. (a) Height distributions of $6 \mathrm{~T}$ sub-monolayer films $v s$ the substrate temperature $T_{S}$ and postannealing process. Each curve has two Gaussian peaks: the first, with lower height values, is the substrate height distribution, while the second one is the height distribution of the 6T island (in the $x$ axis are reported $h$ values while in the $y$ axis peaks densities \# [38]). (b) The substrate peak evolves with $T_{S}$ and post-annealing process, suggesting a fully molecular reorganization for $100+\mathrm{A}$ samples where the peak is aligned to the height distribution peak of the bare $\mathrm{SiO}_{\mathrm{x}}$ (dotted line). (c) Sketches of molecular organization inferred by height measurements. Face-on molecular aggregates $(\delta 1$ and $\delta 2)$ are present on both $\mathrm{SiO}_{\mathrm{x}}$ and $6 \mathrm{~T}$ island, respectively. The expected height of the $6 \mathrm{~T}$ island, i.e. $2.4 \mathrm{~nm}$, is indicated as $h_{i}$. (d) Temperature evolution of islands heights in attractive and repulsive regimes. 
The absolute position of the substrate peak can give insights on the re-organization process of face-on molecules deposited on the $\mathrm{SiO}_{\mathrm{x}}$ substrate. As shown in Figure 3b, its position shifts towards lower values both with increasing $T_{S}$ and post-deposition annealing (continuous lines), reaching the position of the bare $\mathrm{SiO}_{\mathrm{x}}$ peak (dotted line) for films grown at $100^{\circ} \mathrm{C}$ with post-deposition treatment. This evolution suggests a re-organization of faceon molecules deposited on the $\mathrm{SiO}_{\mathrm{x}}$ substrate that, progressively, is ridded from molecules.

The height $h$ of a $6 \mathrm{~T}$ island was measured by subtracting its peak position (scattered around $4 \mathrm{~nm}$ ) to the position of the substrate peak (close to $0.5 \mathrm{~nm}$ ).

For a $6 \mathrm{~T}$ island grown on a bare $\mathrm{SiO}_{\mathrm{x}}$ surface (ideal case, sketch of Figure 3c-i), the island height $h$ should matches the crystal cell parameter $a$, i.e. $h=h_{i} \sim 2.4 \mathrm{~nm}$ [13]. The force $F_{t s}$ applied for imaging the 6T sample affects, as expected, the height $h$ measured in ICM. Compared to the uncompressible $\mathrm{SiO}_{\mathrm{x}}$ substrate, the tip indentation of the $6 \mathrm{~T}$ island is $\sim 1 \AA$ for $F_{t s} \sim 0.5 \mathrm{nN}$, while it exceeds $3 \AA$ for $F_{t s}>2 \mathrm{nN}$ [79]. Such indentation reduces $h_{i}$.

In the real cases discussed above, the presence of face-on molecular aggregates on the $\mathrm{SiO}_{\mathrm{x}}$ substrate should reduce $h$ to $h_{i}-\delta 1$, where $\delta 1$ is the average aggregates thickness (sketch of Figure 3c-ii). This reduction is valid for both gentle and relatively strong forces. In the same force scenario, face-on molecular aggregates deposited on the islands top should increase their height from $h$ to $h_{i}+\delta 2$, where $\delta 2$ is the average aggregates thickness (sketch of Figure 3c-iii).

The plot of $h v s T_{S}$ follows a step function in both attractive (gentle force, $F_{t s} \sim 0.6$ $\mathrm{nN}$ ) and repulsive (relatively strong force, $F_{t s} \sim 2.5 \mathrm{nN}$ ) regimes ${ }^{\mathrm{c}}$. In the attractive regime, where the tip indentation $(\sim 1 \AA)$ is included within the experimental error, $h$ is reduced from (4.0 \pm 0.3$)$ to $(3.1 \pm 0.3) \mathrm{nm}$ for $T_{S}>80^{\circ} \mathrm{C}$ (Figure 3d). Both values are higher than 2.4 $\mathrm{nm}$, confirming the presence of face-on molecular aggregates with thickness $\delta 2$ on the island top. Moreover, $\delta 2$ becomes thinner for $T_{S}>80{ }^{\circ} \mathrm{C}$ due to the molecular reorganization induced by both the higher substrate temperature $\left(100{ }^{\circ} \mathrm{C}\right)$ and the postdeposition annealing. In the repulsive regime, the plot of $h v s T_{S}$ shows a height reduction from (3.4 \pm 0.3$)$ to $(2.5 \pm 0.3) \mathrm{nm}$ for $T_{S}>80^{\circ} \mathrm{C}$ (Figure 3d). By comparing them to the height

\footnotetext{
${ }^{\mathrm{c}}$ Topographic images in attractive and repulsive regimes are consecutive and performed in the same area.
} 
measured in attractive regime, $h$ is compressed of $\sim 0.6 \mathrm{~nm}$ regardless $T_{S}$. This compression value exceeds the indentation expected for 6T island composed of edge-on molecules (axis $a$ of the crystal cell, indentation between 0.3 and $0.4 \mathrm{~nm}$ [79]), confirming the presence of a compliant layer on the island top with thickness $\delta 2 \sim 2 \AA$ (possibly compressed).

The same thickness has been also measured for the face-on molecular aggregates layer $\delta 1$ on the $\mathrm{SiO}_{\mathrm{x}}$. Being the $\mathrm{SiO}_{\mathrm{x}}$ uncompressible even at the maximum applied force $\left(F_{t s} \sim 2.5 \mathrm{nN}\right)$, the shift of the substrate peak observed by switching from attractive to repulsive regime can be ascribed only to a compliant molecular layer.

As suggested by Palacios-Lidòn et al [80], height measurements performed in CM are useful to confirm the height measurements performed in ICM. Within the experimental errors, the plot of $h v s T_{S}$ measured in CM (not shown) is equal to the one observed in the ICM repulsive regime, being the force employed in CM measurements $\sim 15 \mathrm{nN}$.

In view of these results, sub-monolayer $6 \mathrm{~T}$ films can be envisioned as composed of islands formed by edge-on molecules ( $2.4 \mathrm{~nm}$ high) on top of which is present a layer of face-on molecules $(\delta 2)$, like the one deposited on $\operatorname{SiO}_{\mathrm{x}}(\delta 1)$. This scenario is similar to one described for PTCDA on $\operatorname{Ag}(111)$ [81,82], where a morphological transition of islands for $T_{S} \sim 70^{\circ} \mathrm{C}$ is observed and a smoothening of the film interface for $T_{S}>85{ }^{\circ} \mathrm{C}$ is modelled.

\subsection{Indirect evidences of molecular re-organization by Scanning Probe Microscopy measurements}

Beyond the morphological changes of 6T sub-monolayer films, SPM techniques can probe the re-organization process of face-on molecules deposited on the $\mathrm{SiO}_{\mathrm{x}}$ substrate with high spatial resolution. To date, organic molecules deposited on chemically inert substrates [83], like $\mathrm{SiO}_{\mathrm{x}}$, are weakly bonded hence molecular imaging cannot be achieved [84]. Accordingly, SPM can image only large enough aggregates of such molecules and measure their effect on the physical properties of the surface. By focussing on the face-on molecular aggregates inferred by morphological analysis, SPM was employed to investigate the mechanical and the tribological properties of the $\mathrm{SiO}_{\mathrm{x}}$ surface with (and without) post-deposition annealing. Experimental results were compared to the bare $\mathrm{SiO}_{\mathrm{x}}$ for evaluating the efficiency of the annealing process.

\subsubsection{Stiffness imaging of face-on molecular aggregates on $\mathrm{SiO}_{\mathrm{x}}$}


Phase ICM measurements were performed for identifying aggregates of face-on molecules with high spatial resolution. Figure 4 shows ICM topographic (Figure 4a, in attractive regime) and phase images in attractive (Figure $4 b$ ) and repulsive (Figure $4 c$ ) regimes for films grown at $80^{\circ} \mathrm{C}$.

The topographic image presents two regions with homogenous contrast: the substrate (dark region) and the 6T island (light region in the upper part of Figure 4a). Although the substrate appears featureless, a topographic profile cutting it transversely (red line in the image) shows a relatively large height modulation (red continuous line in the lower plot, maximum peak-to-valley roughness $R_{t} \sim 8 \AA$ [38]) compared to the one observed on bare $\mathrm{SiO}_{\mathrm{x}}$ (brown dashed line in the lower plot, $R_{t} \sim 4 \AA$ ). Such difference hints at the presence of molecular aggregates that modulate the topography of the submonolayer substrate. The same topographic profile collected in repulsive regime (not shown) supports this hypothesis: when $F_{t s}$ increases in the repulsive regime, the profile modulation (green dashed line $R_{t} \sim 4 \AA$ ) is reduced to a value comparable to the bare $\mathrm{SiO}_{\mathrm{x}}$. This result is a further proof that the substrate of $6 \mathrm{~T}$ sub-monolayer films is covered by face-on molecular aggregates forming a compliant molecular layer that is compressed when $F_{t s}$ increases.
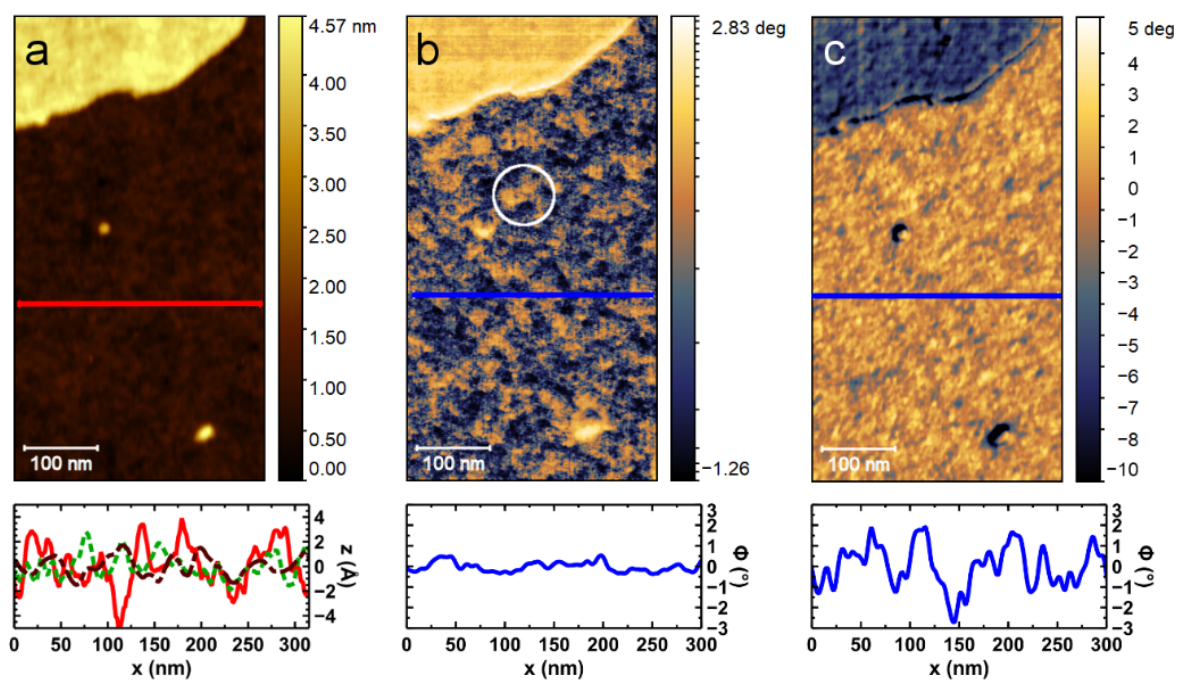

Figure 4. Topographic (a) and phase images in attractive (b) and repulsive (c) regimes of the substrate close to a portion of an island situated on the upper part of images. Plots of topographic (a) and phase (b, c) profiles are reported below images. Profiles were measured along the sketched lines. Topographic and phase images were acquired in attractive regime with a force $F_{t s}$ of $0.13 \mathrm{nN}$, while the phase image in repulsive regime was acquired with a force $F_{t s}$ of $0.20 \mathrm{nN}$. Images processing procedures: Topographic image was flattened with 
a mean plane and a polynomial background (second order) was subtracted for correcting the image. The minimum height value of the image was set to zero. For soak of comparison, phase images were flattened with mean plane then it was set to zero. This operation allows a straightforward comparison between phase profiles. Profiles represented in plots is an averaged profile of seven contiguous line profiles.

Phase images enabling a better discernment of the face-on molecular aggregates deposited on the $\mathrm{SiO}_{\mathrm{x}}$ substrate. In the attractive regime, the modulation of the phase on the substrate suggests the presence of small aggregates (see for instance the circled region of Figure 4b). Due to the low force applied, phase shifts do not exceed $1^{\circ}$ (phase profile in the lower plot). Vice versa, the line profile in repulsive regime has large phase modulation of few degrees, although the phase image of the substrate shows a homogenous contrast. The origin of such modulation lies into both surface organization and applied force. Faceon molecular aggregates form a pattern on the $\mathrm{SiO}_{\mathrm{x}}$ surface with interstices where the $\mathrm{SiO}_{\mathrm{x}}$ surface is exposed. Assuming a Young modulus for face-on molecules of $\sim 1 \mathrm{GPa}$ (similar to the one reported in the literature [85]), phase imaging distinguishes the stiffness difference between the soft molecular aggregates (bright regions) with respect to the rigid $\mathrm{SiO}_{\mathrm{x}}$ (Young modulus $\sim 70 \mathrm{GPa}$, dark spots). The higher force applied in the repulsive regime homogenise the phase contrast due to the uniaxial compression of molecular aggregates (the thickness is reduced but the area is expanded), while the contrast is enhanced on the exposed $\mathrm{SiO}_{\mathrm{x}}$. This phase contrast interpretation agrees to the one reported in ref. [46].

By means of the local stiffness $\langle S\rangle$, as calculated from phase images through Eq. 1, the mechanical responses of $6 \mathrm{~T}$ sub-monolayer films $v s T_{S}$ and annealing can be determined qualitatively. As reported in section 2.2, the overall derivative forces exercised by the tip on the sample in the repulsive regime can be approximated to the local sample stiffness $\langle S\rangle$. Herein, larger is the phase shift (with respect to $90^{\circ}$ ) stiffer is the material. The substrate is expected having lower $\phi_{S}$ values with respect to both 6T island $\phi_{6 T}$ and face-on molecular aggregates $\phi_{S, 6 T}\left(\phi_{S}<\phi_{6 T}, \phi_{S, 6 T}<90^{\circ}\right.$, i.e. $\Delta \phi_{S}>\Delta \phi_{6 T}=90^{\circ}-\phi_{6 T}, \Delta \phi_{S, 6 T}=90^{\circ}-$ $\phi_{S, 6 T)}$ [86]. This agrees qualitatively to the profile of Figure 3c. The stiffness calculated on the substrate between $6 \mathrm{~T}$ islands is useful for proving the re-organization of face-on molecular aggregates induced by both temperature and annealing: as shown in Figure 5a, its stiffness $\langle S\rangle$ increases in both cases until the $\mathrm{SiO}_{\mathrm{x}}$ stiffness is recovered for the $100+\mathrm{A}$ 
sample. Concordantly, a similar trend of the photoluminescence emission selectively correlated to face-on molecule aggregates is measured by integrating the pixel intensity in Confocal Laser Scanning Microscope images collected for the different samples (see SI).
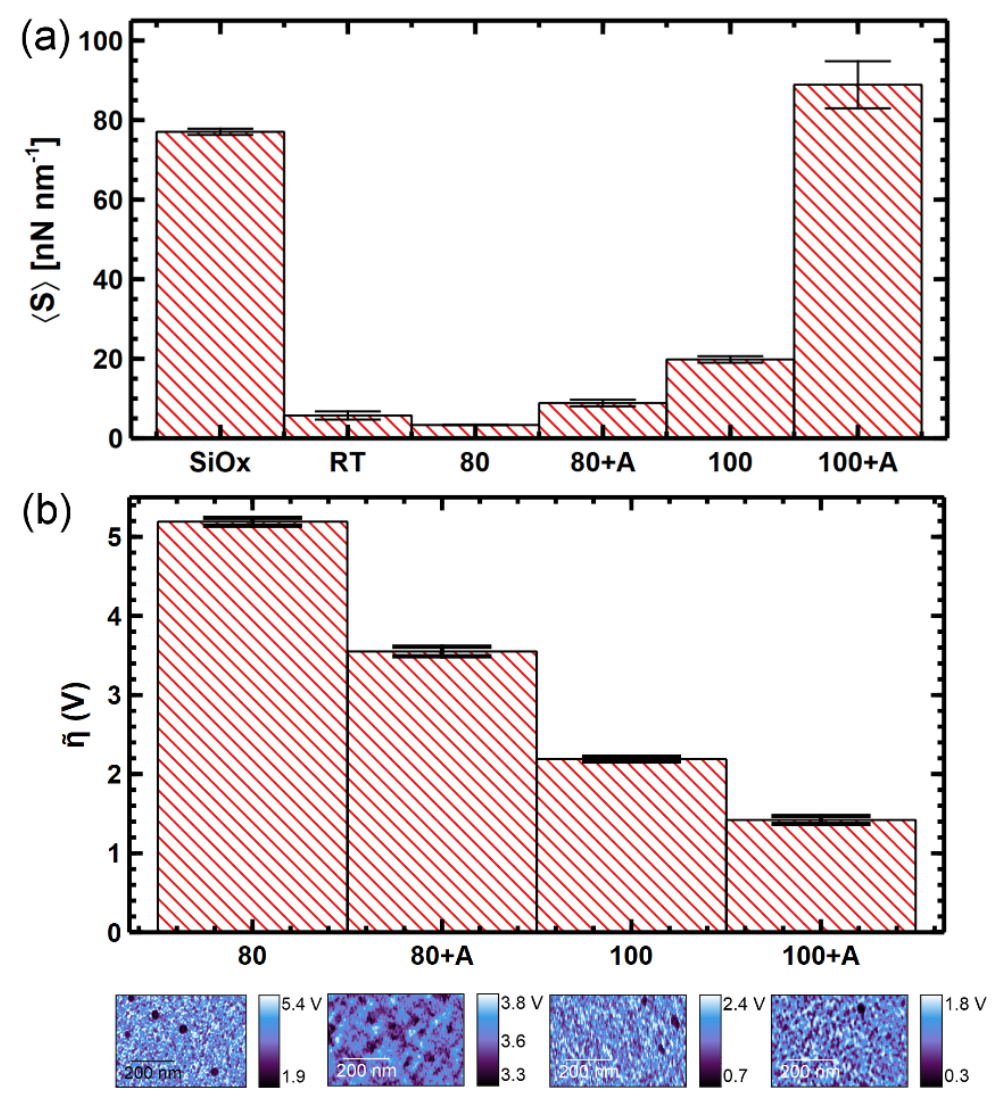

Figure 5. (a) Substrate stiffness $v s T_{S}$ calculated from phase imaging (6T islands are excluded). Data were normalized with respect to both the minimum $A_{S P} / A_{0}$ and the maximum free oscillation amplitude of the cantilever $A_{0}$. (b) Graph: Evolution of the mean tip indentation $\tilde{\eta}$ (in V) for increasing temperature and postdeposition annealing; Bottom part: Ultrasonic images of the substrate between 6T islands for films grown at $80^{\circ} \mathrm{C}, 80+\mathrm{A}, 100^{\circ} \mathrm{C}$ and $100+\mathrm{A}$ (from left to right).

Ultrasonic Force Microscopy (UFM) measurements gives additional insights on the pattern formed by the face-on molecular aggregates. As reported in the literature, the ultrasonic contrast (UC) is highly sensitive to material stiffness, i.e. elastic and adhesive properties [52]. Qualitatively, the higher is the elastic modulus $E$ of the area under investigation (stiffer material), the smaller is the tip indentation $\eta$ (in V) ${ }^{\mathrm{d}}$ and the larger is the additional deflection induced by ultrasonic vibrations (cf. Section 2) [87]. UFM is also

\footnotetext{
d The tip indentation is, on first approximation, inversely proportional to UC (in V). The calibration for converting $\mathrm{V}$ to $\mathrm{nm}$ (
} 
suitable for inspecting soft samples without damage because, if the ultrasonic vibration has sufficiently high amplitude, nanoscale friction is reduced or nullified [88].

Figure 5b (lower part) shows representative portions of UFM images of samples grown at different $T_{S}$, with and without post-deposition annealing (from left and to right). By imaging 6T sub-monolayer films with the same force $\left(F_{N} \sim 15 \mathrm{nN}\right)$, the distribution of the indentation $\eta$ on the substrate can be compared. These distributions are homogeneous in all cases ( $\eta$ values follow Gaussian distributions); bright and dark regions are balanced on average, with the rare exception of dark areas that can be attributed to randomly distributed 6T agglomerates. The mean values $\tilde{\eta}$ of Gaussian distributions decrease monotonically with increasing $T_{S}$ and post-deposition annealing, from $(5.19 \pm 0.05)$ to $(1.42 \pm 0.05) \mathrm{V}$ (see the graph of Figure $5 b$ ).

This trend indicates a progressive reduction of the tip indentation $\tilde{\eta}$, which corresponds to an increased elastic modulus and/or a decreased surface adhesion [53]. On first approximation, the trend concords with the increasing of the local stiffness $\langle S\rangle$ measured by phase imaging, being $\langle S\rangle$ proportional to the elastic modulus [46]. The interpretation is however not trivial, as the stiffness may vary in a complex way due to the fact that the substrates are covered with a compliant and adhesive layer composed of faceon molecular aggregates, which progressively re-organize with increasing $T_{S}$ and postdeposition annealing. Furthermore, as the compliant layer progressively disappears, a layer of water starts to cover the hydrophilic native silicon oxide. UFM data thus reflect this complex scenario.

\subsubsection{Friction imaging of face-on molecular aggregates on $\mathrm{SiO}_{\mathbf{x}}$}

LFM measurements were employed to further confirm the molecular reorganization promoted by post-deposition annealing. For instance, Figures $6 \mathrm{a}$ and $6 \mathrm{~b}$ show topographic and calculated difference image of 6T sub-monolayer films grown at $100{ }^{\circ} \mathrm{C}$ with one hour of post-deposition annealing $(100+\mathrm{A})$. Two marked regions are clearly visible: a brighter one with lower friction (substrate) and a darker one with higher friction (6T islands).

In order to verify whether molecules are re-organized by the post-deposition annealing, the friction coefficient $\mu$ of interstitial areas between 6T islands was compared to the one of bare $\mathrm{SiO}_{\mathrm{x}}$ (Figure 6c). For 6T sub-monolayer films grown at $80{ }^{\circ} \mathrm{C}\left(80{ }^{\circ} \mathrm{C}\right.$ 
and $80+$ A samples) $\mu$ is constant to $\sim 0.27$ within experimental errors, confirming that faceon molecular aggregates increase the surface friction. On the other hand, $\mu$ decreases to 0.15 for samples grown at $100{ }^{\circ} \mathrm{C}\left(100{ }^{\circ} \mathrm{C}\right.$ and $100+\mathrm{A}$ samples are equal within experimental errors). This value is comparable to the one of bare $\mathrm{SiO}_{\mathrm{x}}$ [89] (see Figure 6c) proving that post-deposition annealing fully re-organizes the face-on molecular aggregates on the $\mathrm{SiO}_{x}$ substrate.
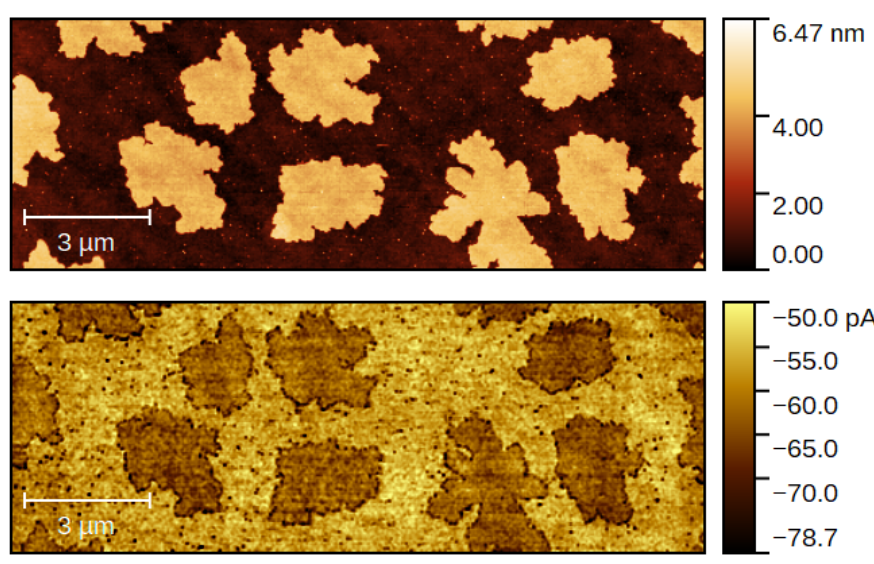

(a)

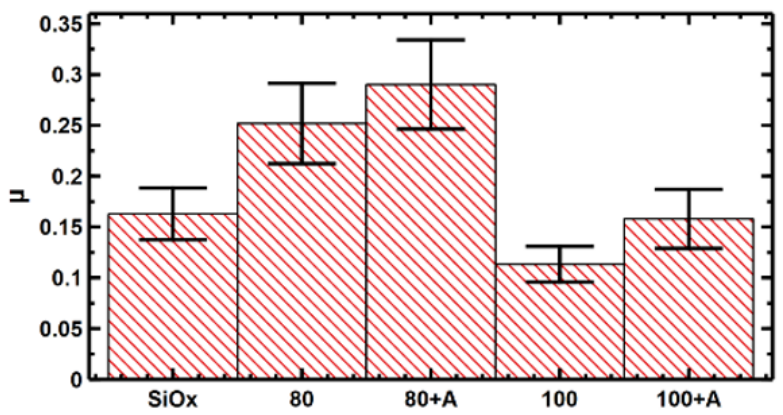

(b)

(c)

Figure 6. (a) Topographic image of $6 \mathrm{~T}$ islands grown on native $\mathrm{SiO}_{\mathrm{x}}$ and (b) correspondent friction image obtained by subtracting retrace to trace scans (see SI for a detailed description of the lateral force signal). (c) Evolution of the friction coefficient $\mu$ of the substrate (6T islands are excluded) $v s$ substrate temperature and post-deposition annealing, compared to the bare $\mathrm{SiO}_{\mathrm{x}}$.

\subsection{Molecular dynamics simulations of face-on molecular aggregates}

In first set of simulations (SA), we focused on the very local aspects of the island growth and more specifically on the temperature-dependent probability for face-on molecules near the edge of a $6 \mathrm{~T}$ island, to stand-up and contribute to its growth. Figure $7 \mathrm{a}$ shows a snapshot of the initial configuration of these simulations, which we conducted for $40 \mathrm{~ns}$ at 27 and $127^{\circ} \mathrm{C}$. At $27^{\circ} \mathrm{C}$ no appreciable changes were observed in the time window covered by our simulations, while at $127^{\circ} \mathrm{C}$ the enhanced molecular motion allows for 
some qualitative differences (Figure 7b). In fact, we observe that some molecules approach the terrace edge and eventually turn in an upright position, leading to an accretion of the island as indirectly observed in the annealing experiments. Conversely, we did not observe sizable positional displacements for molecules initially belonging to the island.

A second series of simulations (SB) was carried out to gain microscopic insight on the non-crystalline " $\delta 1$ " aggregates of face-on molecules imaged by UFM (Figure $7 \mathrm{~g}, \mathrm{~h}$ ). The aggregates were produced by deposition from vacuum and are shown in Figure 7c, while the same systems after the removal of diffusing molecules in a time interval of $70 \mathrm{~ns}$ at $80{ }^{\circ} \mathrm{C}$ is depicted in Figure $7 \mathrm{~d}$. The main observation here is that, at the chosen temperature, face-on molecules are able to detach from the mounds and diffuse, again consistently with the experimental observation. The comparison of the snapshots with topography maps (Figure 7e,f) indicates that heights of 0.3-0.6 and 0.6-0.9 nm correspond to single molecules or two stacked molecules, respectively. The topographic images collected by UFM of $20 \mathrm{~nm}$ x $20 \mathrm{~nm}$ regions on the $\mathrm{SiO}_{\mathrm{x}}$ substrate are featureless, while the ultrasonic signal reveals qualitatively two zones with different stiffness. As shown in Figure 7, samples as deposited (g) and annealed (h) differs for the surface coverage of stiffer zones (black and dark blue), passing from 30 to $50 \%$. The overall consistency between the topography maps from simulations and those from UFM supports the validity of structural model of disordered aggregates gained from MD. 
(a)

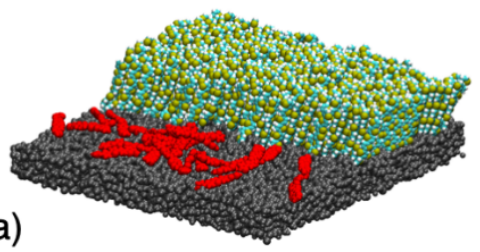

(c)

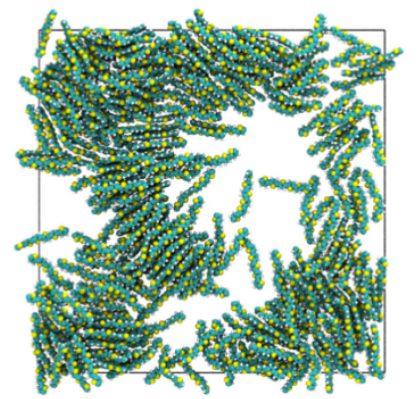

(e)

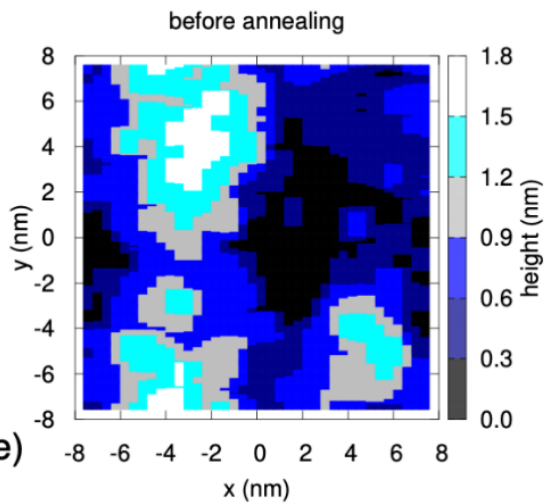

(g)
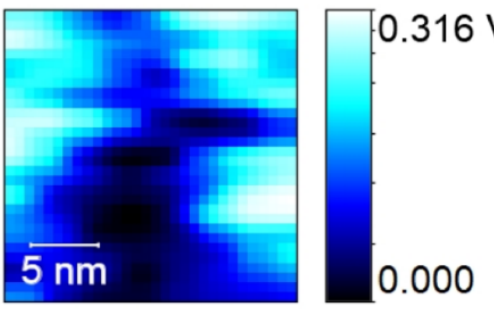

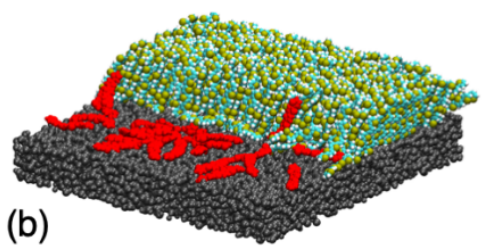

(d)
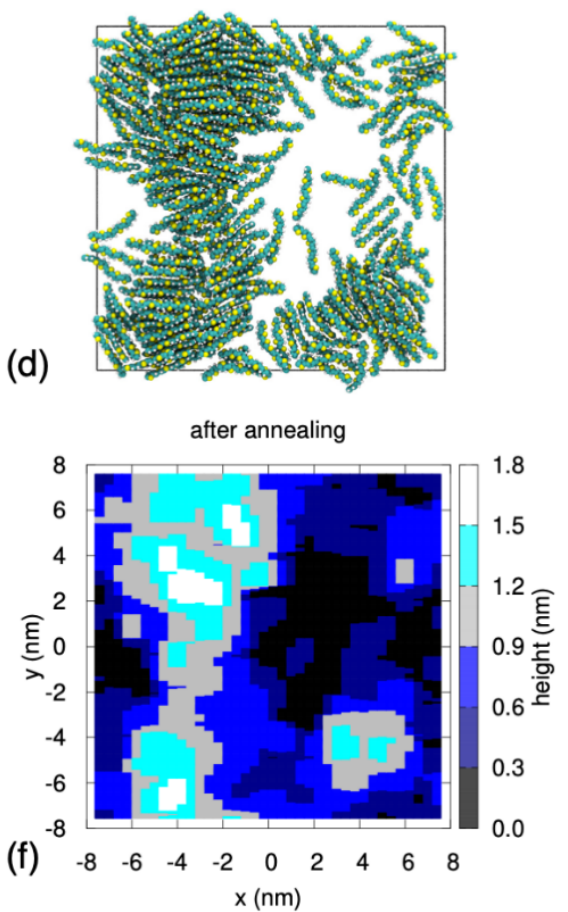

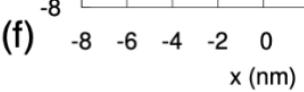

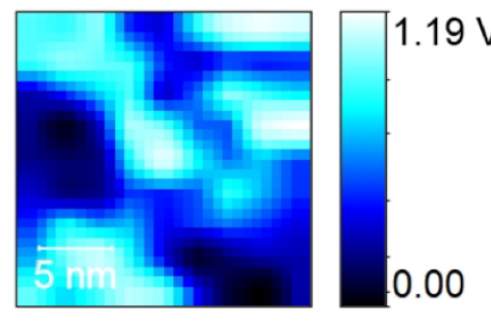

Figure 7. (a)(b) Selected snapshots for molecular dynamics simulations of $\mathrm{SiO}_{2}$ surface approximately halfcovered by a $6 \mathrm{~T}$ crystalline island and by 24 face-on $6 \mathrm{~T}$ molecules (in red). The snapshots show the starting configuration (a) and after $15 \mathrm{~ns}$ of simulation at $127^{\circ} \mathrm{C}(\mathrm{b})$, where some of the initially flat molecules have merged to the island. Substrate atoms (topmost $1 \mathrm{~nm}$ ) are colored in gray. (c) Snapshot of a sample vapor deposited at $277^{\circ} \mathrm{C}$, consisting of 300 molecules. (d) Snapshot of the same sample after removing 60 molecules showing a diffuse behaviour in the time interval of $70 \mathrm{~ns}$ at $80^{\circ} \mathrm{C}$. Silica is not shown for clarity. (e)(f) Topographic maps calculated for the samples are compared to UFM images of two substrate regions for $80(\mathrm{~g})$ and $80+\mathrm{A}(\mathrm{h})$. Such images show a molecular reorganization recalling the simulated topographic maps. 
In order to obtain a more quantitative picture of the diffusivity of $6 \mathrm{~T}$ on silica, in a third series of simulations (SC) we studied the temperature dependence of the 2D motion for a system at low coverage, shown in the inset of Figure 8a. We followed the trajectory of each molecule $j$ by tracking its instantaneous position $\boldsymbol{r}_{j, k}=\left(x_{j, k}, y_{j, k}, z_{j, k}\right)$ at time $t_{k}=$ $k \Delta t$, using a $\Delta t$ of $20 \mathrm{ps}$ and a trajectory length of $M \Delta t=40 \mathrm{~ns}$ ( $M=2000$ frames). We then obtained the molecular mean square displacement (MSD) of each component $x, y, z$ as a function of time, by averaging over the different time origins:

$$
\overline{\Delta x_{j}{ }^{2}(t)}=\overline{\Delta x_{j}{ }^{2}(k \Delta t)}=\frac{1}{M-k} \sum_{i=1}^{N-k}\left(x_{j, i+k}-x_{j, i}\right)^{2}
$$

The ensemble average over independent trajectories (molecules) can be obtained by averaging the MSDs computed for each of them:

$$
\left\langle\Delta x^{2}(t)\right\rangle=\frac{1}{N} \sum_{j=1}^{N} \overline{\Delta x_{j}^{2}(t)}
$$

The $z$ component was monitored to keep track of desorption events: only one at 277 ${ }^{\circ} \mathrm{C}$ was reported in the $40 \mathrm{~ns}$ observation window. The $x, y$ components were used to compute the on-surface diffusion coefficient following Einstein's formula:

$$
D=\lim _{t \rightarrow \infty} \frac{\left\langle\Delta x^{2}(t)\right\rangle+\left\langle\Delta y^{2}(t)\right\rangle}{4 t}
$$

We verified that the linear behavior can attained in 10 ns (at least for some molecules, see discussion below). The logarithm of the calculated diffusion coefficient is plotted as a function of inverse temperature in Figure 8a as black squares. The points seem to approximately follow a straight line like expected for an activated process, like e.g. the typical behavior observed in a liquid or liquid crystalline phase [57]. Actually, this Arrhenius analysis implies the assumption of a diffusive behavior for all the molecules of the system, but is this hypothesis correct? To answer this question, we inspected all the individual $\overline{\Delta x_{\mathrm{J}}^{2}(t)}$ and $\overline{\Delta y_{\mathrm{J}}^{2}(t)}$ at the different temperatures, observing that: (i) the diffusive behavior is attained only by a fraction of molecules that increases with temperature; (ii) the diffusive behavior is shown only at "short" times, typically up to 5-10 ns; (iii) some molecules do not move during the observation time; and (iv) the picture is nevertheless dynamic with molecules getting trapped and de-trapped in a trajectory, or the 
same molecule being mobile at one temperature and fixed at another one. Similar situations are faced in the context of single particle tracking experiments, typically following at regular time intervals the trajectories of some living cells on a surface, or of proteins on a membrane. In fact, it is well known that in these systems some objects are immobile or exhibit only sub-linear increase with time of their MSD [90]. In addition, the individual molecules diffusion coefficients cannot be calculated with Eq. 3, but are better captured with a linear fit with the following expression:

$$
\left\langle\Delta x_{j}^{2}(t)\right\rangle+\left\langle\Delta y_{j}^{2}(t)\right\rangle=C_{j}+4 D_{j} t
$$

where the constant $C$ accounts for some local fluctuations of the position when the object is trapped. Furthermore, it was first recognized by Saxton [91] that, to avoid unphysical results such as negative diffusion coefficients, the fit with Eq. 6 must be performed in portions of the trajectory much shorter than the total observation time. We then proceeded in analyzing the individual MSDs within this framework. As Eq. 6 only applies to diffusing molecules, it was necessary to classify the MSD behavior of all the molecules in the system. For this purpose, we established two arbitrary thresholds on the basis of the visual inspection of each MSD(t) profile. We classified as "fixed" all molecules with $\operatorname{MSD}(t)<2.5 \mathrm{~nm}^{2}$ in the time interval of 30ns, as diffusing the ones with $\operatorname{MSD}(t)>$ $10 \mathrm{~nm}^{2}$, and as mobile (but with sublinear behavior) the ones with intermediate $\operatorname{MSD}(\mathrm{t})$. We recalculated the diffusion coefficients for diffusing molecules with Eq. 6, plotted in Figure 8a as green circles. Now two regimes with two different activation energies appear: at low temperatures, only a few $6 \mathrm{~T}$ molecules move on the silica surface where the high energy positions (the traps) are occupied by fixed molecules, while at high $\mathrm{T}$ almost all the molecules move on an energetically rougher surface, consistently with the higher activation energy given by the Arrhenius fit.

The above analysis is useful for understanding qualitatively what happens to $6 \mathrm{~T}$ molecules on $\mathrm{SiO}_{2}$ as a function of temperature, with the help of the histogram in Figure 8b. Close to room temperature, most of molecules is either fixed or moving from one trap to another; only above $100{ }^{\circ} \mathrm{C}$ a consistent fraction of molecules has attained a diffusive behavior, with that fraction steadily increasing with T. Moreover, diffusing molecules can cover distances of the order of hundreds of microns in one hour at $127{ }^{\circ} \mathrm{C}$ and hence can virtually reach the growing islands (tens of microns). On the other hand, at room 
temperature it is then unlikely that deposited molecules landing on the surface far away from an island are able to travel for distances large enough to reach it during the annealing time.

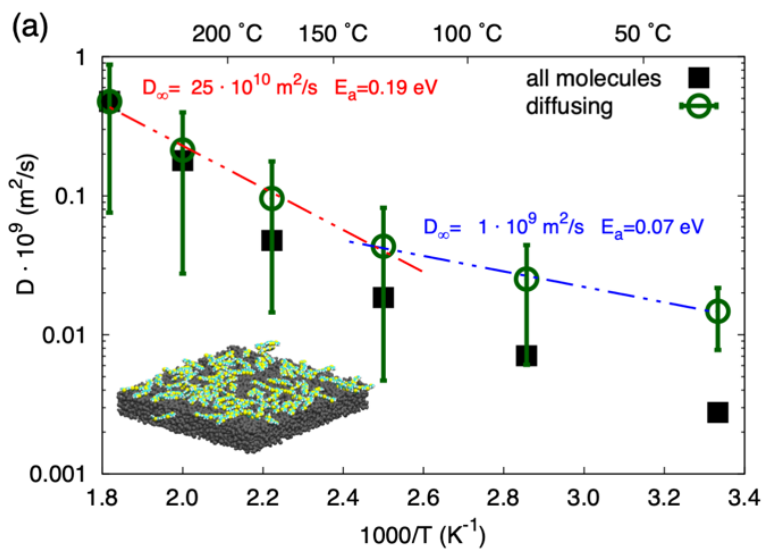

(b)

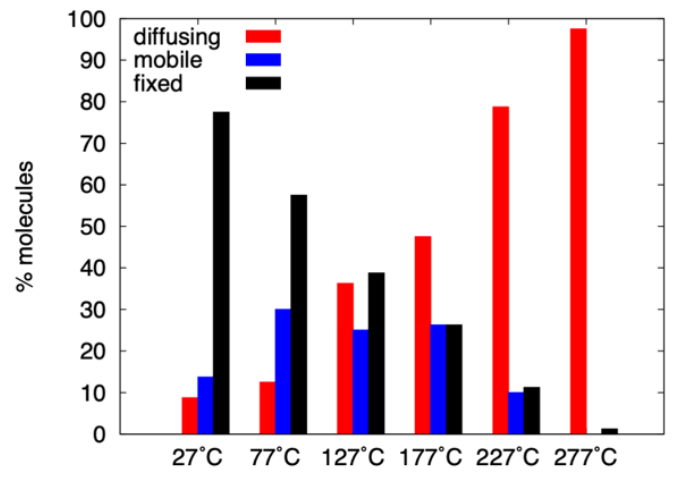

Figure 8. (a) Arrhenius plot of the simulated diffusion coefficient of $\mathrm{T} 6$ molecules on $\mathrm{SiO}_{2}$, evaluated from the sample shown in the inset: calculated with Eq. 3 for all molecules (black squares), calculated only for diffusing molecules (green circles, and vertical bars for standard deviations). Dot-dashed lines are Arrhenius fits with $\mathrm{D}(\mathrm{T})=\mathrm{D}_{\infty} \mathrm{e}^{-\mathrm{E}_{\mathrm{A}} /(\mathrm{kT})}$ for diffusing molecules at $\mathrm{T} \leq 127^{\circ} \mathrm{C}$ (blue line) and at $\mathrm{T} \geq 127^{\circ} \mathrm{C}$ (red line). (b) Histogram showing the classification of the dynamic diffusive behavior of $6 \mathrm{~T}$ molecules on silica at the different temperatures.

\subsection{Realization of a complete 6T monolayer via post-deposition annealing}

Once obtained insights on re-organization phenomena of face-on molecules, such knowledge was exploited to demonstrate the possibility of growing a complete 6T monolayer via sequential post-deposition annealing (Figure 9). The need for introducing a new protocol for realizing a complete monolayer originates from the experimental difficulties in controlling the growth of a single monolayer by simply interrupting the molecular flux of an OMBD system (see Figure S7 in SI - $150 \mathrm{ng}$ of 6T was deposited on $\mathrm{SiO}_{\mathrm{x}}$ in one-step) $[18,32,92]$. The method introduced herein enables to obtain a $6 \mathrm{~T}$ 
monolayer by depositing $150 \mathrm{ng}$ in a sequence of three $50 \mathrm{ng}$ depositions, spaced out by two post-deposition annealing at $T_{S}=100{ }^{\circ} \mathrm{C}$, each of them 1 hour long (intermediate growth steps after annealing at $\theta \sim 33 \%$ and $\theta \sim 66 \%$ are shown in the corner of Figure 9).

Monolayer films grown via sequential post-deposition annealing are (quasi) complete, i.e. the surface coverage $\theta$ is $(97 \pm 3) \%$, and homogenous over large area $(5 \mathrm{~mm}$ x $5 \mathrm{~mm}$ ). The film height, as measured seizing on some defects (holes), is (3.3 \pm 0.3$) \mathrm{nm}$ that is in agreement with the height measured in sub-monolayer films (cf. Section 3.4). Differently to the results reported in the literature [18], no islands of the second monolayer were grown on the first monolayer, so such engineered surface mimics (quasi) perfectly the substrate morphology.

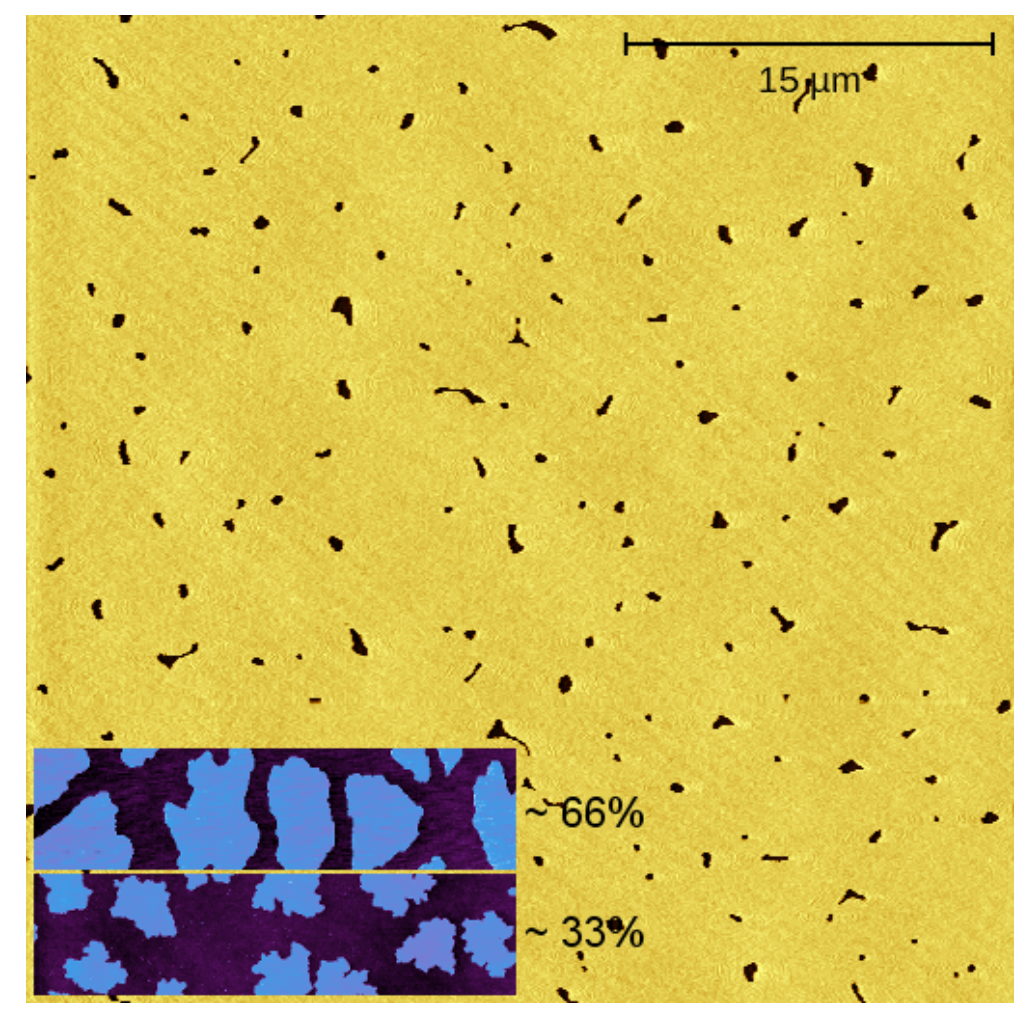

Figure 9. Topographic image over large area $(40 \mu \mathrm{m} \times 40 \mu \mathrm{m}$, z-scale from 0 to $4.3 \mathrm{~nm})$ of a complete monolayer grown at $T_{S}=100{ }^{\circ} \mathrm{C}$ with post-deposition annealing. Insets: Topographic images of postdeposition annealing steps after the first $50 \mathrm{ng}$ deposition (bottom inset figure, $\sim 33 \%$ ) and the second $50 \mathrm{ng}$ deposition (top inset figure, $\sim 66 \%$ ). Similarly results were obtained for monolayers grown at $T_{S}=80{ }^{\circ} \mathrm{C}$ with post-deposition annealing, although at lower $T_{S}$ re-organization of face-on molecules is disordered [92].

This method introduces a new protocol for surface engineering employing a large set of small molecules used as a traditional standard in organic electronics [93,94]. It allows employing such molecules in order to develop functional surfaces with different chemical 
interfaces. Pentacene and PDI8-CN2 were recently used from this perspective in order to tune the cell-surface interactions [95]. They enable a more precise investigation of the cellsurface interaction, introducing a "morphological figure of merit" for defining it.

\section{Conclusions}

Sexithiophene sub-monolayer films grown at different substrate temperatures (from 25 to $120^{\circ} \mathrm{C}$ ) with a constant amount of deposited molecules, and underwent (or not) to a post-annealing process at $80{ }^{\circ} \mathrm{C}$ and $100{ }^{\circ} \mathrm{C}$ were investigated by using Scanning Probe Microscopy techniques. Morphological, tribological and mechanical measurements, and computer simulations consistently show evidences that face-on molecular aggregates exist on the $\mathrm{SiO}_{\mathrm{x}}$ surface and they can be re-organized by means of a post annealing process. In particular, the sample grown at $100{ }^{\circ} \mathrm{C}$ and post-annealed for $1 \mathrm{~h}$ has shown a complete molecular re-organization, as proved by both friction and stiffness values equal to the ones of the bare $\mathrm{SiO}_{\mathrm{x}}$ substrate.

On the basis of these results, it was possible to grow uniform and a complete $6 \mathrm{~T}$ monolayer by depositing molecules in three deposition steps, spaced out by two postdepositions annealing 1 hour-long, for substrate temperatures $T_{S}$ of 80 and $100{ }^{\circ} \mathrm{C}$. This multi-step method permits to obtain a $6 \mathrm{~T}$ monolayer with unprecedented control of the surface coverage and paves the way to a new route for the surface engineering of $\mathrm{SiO}_{\mathrm{x}}$. The method presented herein has shown how defects on surface coverage homogeneity and thickness uniformity introduced by the commonly used chemical approach can be overcome by organic molecular beam deposition driven by post-deposition processes.

\section{Acknowledgments}

The authors would like to thank Franco Dinelli for useful suggestions and discussions on UFM and Oleg Kolosov for giving access to the Ultrasonic Force Microscopy instrument. SPM images were elaborated with the software Gwyddion [96], data were analysed by the GNU General Public Licensed software QtiPlot and some figures are prepared by the GNU General Public Licensed software Veusz. Moreover, authors acknowledge Paolo Mei, Tiziano Bonfiglioli and Vincenzo Ragona for their technical support. AFM images were partially collected in the SPM@ISMN facility. The work was 
partially supported by EC FP7 ONE-P large-scale project n ${ }^{\circ} 212311$. CA acknowledge the support from the CNR under the program 'Short Term Mobility' in 2009. LM thanks MIUR for financial support through PRIN project 2015XJA9NT "Molecular Organization in Organic Thin Films via Computer Simulation of their Fabrication Processes".

\section{Bibliography}

[1] P. Martin, Introduction to surface engineering and functionally engineered materials, John Wiley \& Sons, 2011.

[2] D.S. A., F. Antonio, R.M. A., M.T. J., Molecular Self-Assembled Monolayers and Multilayers for Organic and Unconventional Inorganic Thin-Film Transistor Applications, Adv. Mater. 21 (2009) 1407-1433. doi:10.1002/adma.200803267.

[3] M. Barbalinardo, D. Gentili, M. Brucale, F. Valle, I. Manet, G. Foschi, M. Zambianchi, M. Melucci, M. Cavallini, Self-protective action in multicomponent fluorescent self-assembled monolayers, RSC Adv. 6 (2016) 17106-17109. doi:10.1039/C5RA27454K.

[4] D. Gentili, M. Barbalinardo, I. Manet, M. Durso, M. Brucale, A. Mezzi, M. Melucci, M. Cavallini, Additive, modular functionalization of reactive selfassembled monolayers: toward the fabrication of multilevel optical storage media, Nanoscale. 7 (2015) 7184-7188. doi:10.1039/C5NR00346F.

[5] K.L. Prime, G.M. Whitesides, Self-assembled organic monolayers: model systems for studying adsorption of proteins at surfaces, Science (80-. ). 252 (1991) 1164 LP $-1167$.

[6] R.L. McCreery, A.J. Bergren, Surface functionalization in the nanoscale domain, in: Nanofabrication, Springer, 2012: pp. 163-190.

[7] C. Haensch, S. Hoeppener, U.S. Schubert, Chemical modification of selfassembled silane based monolayers by surface reactions, Chem. Soc. Rev. 39 (2010) 2323-2334. doi:10.1039/B920491A.

[8] A. Tan, P. Zhang, Organized Organic Molecular Assemblies A2 - Wandelt, Klaus BT - Encyclopedia of Interfacial Chemistry, in: Elsevier, Oxford, 2018: pp. 267276. doi:https://doi.org/10.1016/B978-0-12-409547-2.12892-6.

[9] J. Yang, D. Yan, Weak epitaxy growth of organic semiconductor thin films, Chem. 
Soc. Rev. 38 (2009) 2634-2645. doi:10.1039/B815723P.

[10] A. Brillante, I. Bilotti, R.G. Della Valle, E. Venuti, A. Girlando, M. Masino, F. Liscio, S. Milita, C. Albonetti, P. D’Angelo, A. Shehu, F. Biscarini, Structure and dynamics of pentacene on SiO 2: From monolayer to bulk structure, Phys. Rev. B Condens. Matter Mater. Phys. 85 (2012) 1-9. doi:10.1103/PhysRevB.85.195308.

[11] A. Brillante, I. Bilotti, C. Albonetti, J.-F. Moulin, P. Stoliar, F. Biscarini, D.M. De Leeuw, Confocal Raman spectroscopy of $\alpha$-sexithiophene: From bulk crystals to field-effect transistors, Adv. Funct. Mater. 17 (2007). doi:10.1002/adfm.200700004.

[12] A. Brillante, T. Salzillo, R.G. Della Valle, E. Venuti, F. Borgatti, E. Lunedei, F. Liscio, S. Milita, C. Albonetti, Photoluminescence as a probe of molecular organization in PDI8-CN2 ultra-thin films, J. Lumin. 187 (2017). doi:10.1016/j.jlumin.2017.03.058.

[13] J.-F.F. Moulin, F. Dinelli, M. Massi, C. Albonetti, R. Kshirsagar, F. Biscarini, In situ X-ray synchrotron study of organic semiconductor ultra-thin films growth, Nucl. Instruments Methods Phys. Res. Sect. B Beam Interact. with Mater. Atoms. 246 (2006) 122-126. doi:10.1016/j.nimb.2005.12.008.

[14] F. Liscio, C. Albonetti, K. Broch, A. Shehu, S.D. Quiroga, L. Ferlauto, C. Frank, S. Kowarik, R. Nervo, A. Gerlach, S. Milita, F. Schreiber, F. Biscarini, Molecular reorganization in organic field-effect transistors and its effect on two-dimensional charge transport pathways, ACS Nano. 7 (2013) 1257-1264.

[15] P. Annibale, C. Albonetti, P. Stoliar, F. Biscarini, High-Resolution Mapping of the Electrostatic Potential in Organic Thin-Film Transistors by Phase Electrostatic Force Microscopy\&\#x2020, J. Phys. Chem. A. 111 (2007) 12854-12858. doi:doi:10.1021/jp709590p.

[16] F. Liscio, S. Milita, C. Albonetti, P. D’Angelo, A. Guagliardi, N. Masciocchi, R.G. Della Valle, E. Venuti, A. Brillante, F. Biscarini, Structure and morphology of PDI8-CN2 for n-type thin-film transistors, Adv. Funct. Mater. 22 (2012) 943-953.

[17] S.-S. Sun, L.R. Dalton, Introduction to organic electronic and optoelectronic materials and devices, CRC Press, 2016.

[18] F. Dinelli, M. Murgia, P. Levy, M. Cavallini, F. Biscarini, D.M. de Leeuw, 
Spatially Correlated Charge Transport in Organic Thin Film Transistors, Phys. Rev. Lett. 92 (2004) 90-93. doi:10.1103/PhysRevLett.92.116802.

[19] A. Shehu, S.D. Quiroga, P. D’Angelo, C. Albonetti, F. Borgatti, M. Murgia, A. Scorzoni, P. Stoliar, F. Biscarini, Layered Distribution of Charge Carriers in Organic Thin Film Transistors, Phys. Rev. Lett. 104 (2010) 246602. doi:10.1103/PhysRevLett.104.246602.

[20] S.D. Quiroga, A. Shehu, C. Albonetti, M. Murgia, P. Stoliar, F. Borgatti, F. Biscarini, A high-vacuum deposition system for in situ and real-time electrical characterization of organic thin-film transistors, Rev. Sci. Instrum. 82 (2011).

[21] G.H. and C. Teichert, Nucleation and growth of thin films of rod-like conjugated molecules, J. Phys. Condens. Matter. 25 (2013) 143202. http://stacks.iop.org/0953$8984 / 25 / \mathrm{i}=14 / \mathrm{a}=143202$.

[22] Y. Wu, T. Toccoli, N. Koch, E. Iacob, A. Pallaoro, P. Rudolf, S. Iannotta, Controlling the Early Stages of Pentacene Growth by Supersonic Molecular Beam Deposition, Phys. Rev. Lett. 98 (2007) 1-4. doi:10.1103/PhysRevLett.98.076601.

[23] A. Winkler, On the nucleation and initial film growth of rod-like organic molecules, Surf. Sci. 652 (2016) 367-377. doi:https://doi.org/10.1016/j.susc.2016.02.015.

[24] M.A. Loi, E. da Como, F. Dinelli, M. Murgia, R. Zamboni, F. Biscarini, M. Muccini, Supramolecular organization in ultra-thin films of [alpha]-sexithiophene on silicon dioxide, Nat Mater. 4 (2005) 81-85. http://dx.doi.org/10.1038/nmat1279.

[25] A. Moser, I. Salzmann, M. Oehzelt, A. Neuhold, H.-G. Flesch, J. Ivanco, S. Pop, T. Toader, D.R.T. Zahn, D.-M. Smilgies, R. Resel, A disordered layered phase in thin films of sexithiophene, Chem. Phys. Lett. 574 (2013) 51-55. doi:https://doi.org/10.1016/j.cplett.2013.04.053.

[26] B. Scherwitzl, R. Resel, A. Winkler, Film growth, adsorption and desorption kinetics of indigo on SiO2, J. Chem. Phys. 140 (2014) 184705. doi:10.1063/1.4875096.

[27] O.M. Roscioni, G. D’Avino, L. Muccioli, C. Zannoni, Pentacene Crystal Growth on Silica and Layer-Dependent Step-Edge Barrier from Atomistic Simulations, J. 
Phys. Chem. Lett. 9 (2018) 6900-6906. doi:10.1021/acs.jpclett.8b03063.

[28] Y. Zeng, B. Tao, Z. Yin, Molecular orientation transformation of pentacene on amorphous SiO2: A computational study on the initial growth stage of physical vapor deposition, J. Cryst. Growth. 405 (2014) 73-80. doi:https://doi.org/10.1016/j.jcrysgro.2014.07.038.

[29] L. Muccioli, G. D’Avino, C. Zannoni, Simulation of Vapor-Phase Deposition and Growth of a Pentacene Thin Film on C60 (001), Adv. Mater. 23 (2011) 45324536. doi:10.1002/adma.201101652.

[30] E. Da Como, M.A. Loi, M. Murgia, R. Zamboni, M. Muccini, J-Aggregation in $\alpha$ Sexithiophene Submonolayer Films on Silicon Dioxide, J. Am. Chem. Soc. 128 (2006) 4277-4281. doi:10.1021/ja056060s.

[31] F. Dinelli, C. Albonetti, O. V. Kolosov, Ultrasonic force microscopy: Detection and imaging of ultra-thin molecular domains, Ultramicroscopy. 111 (2011) 267272. doi:10.1016/j.ultramic.2010.12.019.

[32] F. Dinelli, J.-F. Moulin, M.A. Loi, E. Da Como, M. Massi, M. Murgia, M. Muccini, F. Biscarini, J. Wie, P. Kingshott, Effects of Surface Chemical Composition on the Early Growth Stages of $\alpha$-Sexithienyl Films on Silicon Oxide Substrates, J. Phys. Chem. B. 110 (2006) 258-263. doi:10.1021/jp053814g.

[33] H. Brune, G.S. Bales, J. Jacobsen, C. Boragno, K. Kern, Measuring surface diffusion from nucleation island densities, Phys. Rev. B. 60 (1999) 5991-6006. https://link.aps.org/doi/10.1103/PhysRevB.60.5991.

[34] C. Albonetti, F. Biscarini, Observation and analysis of flat-lying molecular layer via scanning probe microscopy, Microscopie. 8 (2011) 36-44.

[35] M.E. Behrndt, Deposition and Detection of Ag and Au Films Below 0.01 Monolayer, J. Vac. Sci. Technol. 8 (1971) 724-732. doi:10.1116/1.1315384.

[36] F. Family, Scaling, percolation and coarsening in epitaxial thin film growth, Phys. A Stat. Mech. Its Appl. 266 (1999) 173-185. doi:https://doi.org/10.1016/S03784371(98)00589-5.

[37] J.A. Stroscio, D.T. Pierce, M.D. Stiles, A. Zangwill, L.M. Sander, Coarsening of Unstable Surface Features during Fe(001) Homoepitaxy, Phys. Rev. Lett. 75 (1995) 4246-4249. https://link.aps.org/doi/10.1103/PhysRevLett.75.4246. 
[38] P. Klapetek, D. Necas, C. Anderson, Gwyddion User Guide, n.d.

[39] N.R. Wilson, P.A. Pandey, R. Beanland, J.P. Rourke, U. Lupo, G. Rowlands, R.A. Römer, On the structure and topography of free-standing chemically modified graphene, New J. Phys. 12 (2010) 125010. doi:10.1088/1367-2630/12/12/125010.

[40] R. García, Resolution, Noise, and Sensitivity, Amplitude Modul. At. Force Microsc. (n.d.) 103-115.

[41] R. García, R. Pérez, R. Garcõ, Dynamic atomic force microscopy methods, Surf. Sci. Rep. 47 (2002) 197-301. doi:https://doi.org/10.1016/S0167-5729(02)00077-8.

[42] H. Hölscher, Quantitative measurement of tip-sample interactions in amplitude modulation atomic force microscopy, Appl. Phys. Lett. 89 (2006) 123109. doi:10.1063/1.2355437.

[43] J.E. Sader, J.W.M. Chon, P. Mulvaney, Calibration of rectangular atomic force microscope cantilevers, Rev. Sci. Instrum. 70 (1999) 3967-3969. doi:10.1063/1.1150021.

[44] J.P. Cleveland, B. Anczykowski, A.E. Schmid, V.B. Elings, Energy dissipation in tapping-mode atomic force microscopy, Appl. Phys. Lett. 72 (1998) 2613-2615. doi:10.1063/1.121434.

[45] J.B.P. and W.C. Oliver, Tip Surface Interactions in STM and AFM, Phys. Scr. 1987 (1987) 61. http://stacks.iop.org/1402-4896/1987/i=T19A/a=010.

[46] S.N. Magonov, V. Elings, M.-H.H. Whangbo, Phase imaging and stiffness in tapping-mode atomic force microscopy, Surf. Sci. 375 (1997) L385-L391. doi:https://doi.org/10.1016/S0039-6028(96)01591-9.

[47] G. Haugstad, Atomic force microscopy: understanding basic modes and advanced applications, John Wiley \& Sons, 2012.

[48] S. Sundararajan, B. Bhushan, Topography-induced contributions to friction forces measured using an atomic force/friction force microscope, J. Appl. Phys. 88 (2000) 4825-4831. doi:10.1063/1.1310187.

[49] T. Müller, M. Lohrmann, T. Kässer, O. Marti, J. Mlynek, G. Krausch, Frictional Force between a Sharp Asperity and a Surface Step, Phys. Rev. Lett. 79 (1997) 5066-5069. doi:10.1103/PhysRevLett.79.5066.

[50] O.K. and K. Yamanaka, Nonlinear Detection of Ultrasonic Vibrations in an 
Atomic Force Microscope, Jpn. J. Appl. Phys. 32 (1993) L1095.

http://stacks.iop.org/1347-4065/32/i=8A/a=L1095.

[51] M.T. Cuberes, Mechanical Diode-Based Ultrasonic Atomic Force Microscopies BT - Applied Scanning Probe Methods XI: Scanning Probe Microscopy Techniques, in: B. Bhushan, H. Fuchs (Eds.), Springer Berlin Heidelberg, Berlin, Heidelberg, 2009: pp. 39-71. doi:10.1007/978-3-540-85037-3_3.

[52] D. F., A.H. E., T. N., B.G.A. D., K.O. V., Elastic mapping of heterogeneous nanostructures with ultrasonic force microscopy (UFM), Surf. Interface Anal. 27 (1999) 562-567. doi:10.1002/(SICI)1096-9918(199905/06)27:5/6<562::AIDSIA538>3.0.CO;2-K.

[53] F. Dinelli, M.R. Castell, D.A. Ritchie, N.J. Mason, G.A.D. Briggs, O. V. Kolosov, Mapping surface elastic properties of stiff and compliant materials on the nanoscale using ultrasonic force microscopy, Philos. Mag. A Phys. Condens. Matter, Struct. Defects Mech. Prop. 80 (2000) 2299-2323. doi:10.1080/01418610008216474.

[54] O.M. Roscioni, L. Muccioli, R.G. Della Valle, A. Pizzirusso, M. Ricci, C. Zannoni, Predicting the Anchoring of Liquid Crystals at a Solid Surface: 5Cyanobiphenyl on Cristobalite and Glassy Silica Surfaces of Increasing Roughness, Langmuir. 29 (2013) 8950-8958. doi:10.1021/la400857s.

[55] R.T. Cygan, J.-J. Liang, A.G. Kalinichev, Molecular Models of Hydroxide, Oxyhydroxide, and Clay Phases and the Development of a General Force Field, J. Phys. Chem. B. 108 (2004) 1255-1266. doi:10.1021/jp0363287.

[56] J. Wang, R.M. Wolf, J.W. Caldwell, P.A. Kollman, D.A. Case, Development and testing of a general amber force field, J. Comput. Chem. 25 (2004) 1157-1174. doi:10.1002/jcc.20035.

[57] A. Pizzirusso, M. Savini, L. Muccioli, C. Zannoni, An atomistic simulation of the liquid-crystalline phases of sexithiophene, J. Mater. Chem. 21 (2011) 125-133. doi:10.1039/c0jm01284j.

[58] J.C. Phillips, R. Braun, W. Wang, J. Gumbart, E. Tajkhorshid, E. Villa, C. Chipot, R.D. Skeel, L. Kalé, K. Schulten, Scalable molecular dynamics with NAMD, J. Comput. Chem. 26 (2005) 1781-1802. doi:10.1002/jcc.20289. 
[59] T. Siegrist, R.M. Fleming, R.C. Haddon, R.A. Laudise, A.J. Lovinger, H.E. Katz, P. Bridenbaugh, D.D. Davis, The crystal structure of the high-temperature polymorph of $\alpha$-hexathienyl ( $\alpha-6$ T/HT), J. Mater. Res. 10 (1995) 2170-2173. doi:DOI: 10.1557/JMR.1995.2170.

[60] G. D’Avino, L. Muccioli, C. Zannoni, From Chiral Islands to Smectic Layers: A Computational Journey Across Sexithiophene Morphologies on C60, Adv. Funct. Mater. 25 (2015) 1985-1995. doi:10.1002/adfm.201402609.

[61] F.-J.J. Meyer zu Heringdorf, M.C. Reuter, R.M. Tromp, Growth dynamics of pentacene thin films, Nature. 412 (2001) 517-520. doi:10.1038/35087532.

[62] F. Valle, M. Brucale, S. Chiodini, E. Bystrenova, C. Albonetti, Nanoscale morphological analysis of soft matter aggregates with fractal dimension ranging from 1 to 3, Micron. 100 (2017). doi:10.1016/j.micron.2017.04.013.

[63] T.A. Witten, L.M. Sander, Diffusion-Limited Aggregation, a Kinetic Critical Phenomenon, Phys. Rev. Lett. 47 (1981) 1400-1403. doi:10.1103/PhysRevLett.47.1400.

[64] S. Pratontep, M. Brinkmann, F. Nüesch, L. Zuppiroli, Correlated growth in ultrathin pentacene films on silicon oxide: Effect of deposition rate, Phys. Rev. B. 69 (2004) 165201. doi:10.1103/PhysRevB.69.165201.

[65] S. Pratontep, F. Nüesch, L. Zuppiroli, M. Brinkmann, Comparison between nucleation of pentacene monolayer islands on polymeric and inorganic substrates, Phys. Rev. B. 72 (2005) 85211. doi:10.1103/PhysRevB.72.085211.

[66] Z. Zhang, M.G. Lagally, Atomistic Processes in the Early Stages of Thin-Film Growth, Science (80-. ). 276 (1997) 377 LP - 383. http://science.sciencemag.org/content/276/5311/377.abstract.

[67] J.A.V. and G.D.T.S. and M. Hanbucken, Nucleation and growth of thin films, Reports Prog. Phys. 47 (1984) 399. http://stacks.iop.org/0034-4885/47/i=4/a=002.

[68] M. Brinkmann, S. Pratontep, C. Contal, Correlated and non-correlated growth kinetics of pentacene in the sub-monolayer regime, Surf. Sci. 600 (2006) 47124716. doi:https://doi.org/10.1016/j.susc.2006.07.040.

[69] G.S. Bales, D.C. Chrzan, Transition from Compact to Fractal Islands during Submonolayer Epitaxial Growth, Phys. Rev. Lett. 74 (1995) 4879-4882. 
https://link.aps.org/doi/10.1103/PhysRevLett.74.4879.

[70] J.G. Amar, F. Family, P.-M. Lam, Dynamic scaling of the island-size distribution and percolation in a model of submonolayer molecular-beam epitaxy, Phys. Rev. B. 50 (1994) 8781-8797. doi:10.1103/PhysRevB.50.8781.

[71] A. Amassian, V.A. Pozdin, T. V Desai, S. Hong, A.R. Woll, J.D. Ferguson, J.D. Brock, G.G. Malliaras, J.R. Engstrom, Post-deposition reorganization of pentacene films deposited on low-energy surfaces, J. Mater. Chem. 19 (2009) 5580-5592. doi:10.1039/B907947E.

[72] A.R. Shugurov, A. V Panin, H.-. Chun, V.A. Loginov, Grain growth and thermal stability of Ag thin films, in: Proceedings. 9th Russ. Int. Symp. Sci. Technol. 2005. KORUS 2005., 2005: pp. 528-531. doi:10.1109/KORUS.2005.1507775.

[73] P. Jensen, Growth of nanostructures by cluster deposition: Experiments and simple models, Rev. Mod. Phys. 71 (1999) 1695-1735. https://link.aps.org/doi/10.1103/RevModPhys.71.1695.

[74] C. Albonetti, M. Barbalinardo, S. Milita, M. Cavallini, F. Liscio, J.F. Moulin, F. Biscarini, Selective growth of $\alpha$-sexithiophene by using silicon oxides patterns, Int. J. Mol. Sci. 12 (2011) 5719-5735.

[75] Y. Ni, L.H. He, J. Song, Strain-driven instability of a single island and a hexagonal island array on solid substrates, Surf. Sci. 553 (2004) 189-197. doi:https://doi.org/10.1016/j.susc.2004.01.051.

[76] B. MÜLLER, Natural formation of nanostructures: from fundamentals in metal heteroepitaxy to applications in optics and biomaterial science, Surf. Rev. Lett. 08 (2001) 169-228. doi:10.1142/S0218625X01000859.

[77] Á. Mechler, J. Kopniczky, J. Kokavecz, A. Hoel, C.-G. Granqvist, P. Heszler, Anomalies in nanostructure size measurements by AFM, Phys. Rev. B. 72 (2005) 125407. https://link.aps.org/doi/10.1103/PhysRevB.72.125407.

[78] A. Kühle, A.H. Sorensen, J.B. Zandbergen, J. Bohr, Contrast artifacts in tapping tip atomic force microscopy, Appl. Phys. A. 66 (1998) S329-S332. doi:10.1007/s003390051156.

[79] W. Kamiński, R. Pérez, Mechanical Response and Energy-Dissipation Processes in Oligothiophene Monolayers Studied with First-Principles Simulations, Tribol. 
Lett. 39 (2010) 295-309. doi:10.1007/s11249-010-9662-9.

[80] E. Palacios-Lidón, C. Munuera, C. Ocal, J. Colchero, Contrast inversion in noncontact Dynamic Scanning Force Microscopy: What is high and what is low?, Ultramicroscopy. 110 (2010) 789-800. doi:https://doi.org/10.1016/j.ultramic.2010.01.015.

[81] B. Krause, A.C. Dürr, F. Schreiber, H. Dosch, O.H. Seeck, Late growth stages and post-growth diffusion in organic epitaxy: PTCDA on $\operatorname{Ag}(111)$, Surf. Sci. 572 (2004) 385-395. doi:https://doi.org/10.1016/j.susc.2004.09.011.

[82] B. Krause, A.C. Dürr, K. Ritley, F. Schreiber, H. Dosch, D. Smilgies, Structure and growth morphology of an archetypal system for organic epitaxy: PTCDA on Ag(111), Phys. Rev. B. 66 (2002) 235404. https://link.aps.org/doi/10.1103/PhysRevB.66.235404.

[83] S. Verlaak, S. Steudel, P. Heremans, P. Heremans, D. Janssen, D. Janssen, M.S. Deleuze, Nucleation of organic semiconductors on inert substrates, Phys. Rev. B. 68 (2003) 195409. doi:10.1103/PhysRevB.68.195409.

[84] P. Jelínek, High resolution SPM imaging of organic molecules with functionalized tips, J. Phys. Condens. Matter. 29 (2017) 343002. doi:10.1088/1361-648x/aa76c7.

[85] H. Cun, Y. Wang, S. Du, L. Zhang, L. Zhang, B. Yang, X. He, Y. Wang, X. Zhu, Q. Yuan, Y.-P. Zhao, M. Ouyang, W.A. Hofer, S.J. Pennycook, H. Gao, Tuning Structural and Mechanical Properties of Two-Dimensional Molecular Crystals: The Roles of Carbon Side Chains, Nano Lett. 12 (2012) 1229-1234. doi:10.1021/n1203591t.

[86] N.F. Martínez, W. Kamiński, C.J. Gómez, C. Albonetti, F. Biscarini, R. Pérez, R. García, Molecular scale energy dissipation in oligothiophene monolayers measured by dynamic force microscopy, Nanotechnology. 20 (2009) 434021. doi:10.1088/0957-4484/20/43/434021.

[87] K. Yamanaka, UFM observation of lattice defects in highly oriented pyrolytic graphite, Thin Solid Films. 273 (1996) 116-121. doi:https://doi.org/10.1016/00406090(95)06802-3.

[88] F. Dinelli, S.K. Biswas, G.A.D. Briggs, O. V Kolosov, Ultrasound induced lubricity in microscopic contact, Appl. Phys. Lett. 71 (1997) 1177-1179. 
doi:10.1063/1.120417.

[89] E.-S. Yoon, S.H. Yang, H.-G. Han, H. Kong, An experimental study on the adhesion at a nano-contact, Wear. 254 (2003) 974-980. doi:https://doi.org/10.1016/S0043-1648(03)00302-8.

[90] S. Manley, J.M. Gillette, G.H. Patterson, H. Shroff, H.F. Hess, E. Betzig, J. Lippincott-Schwartz, High-density mapping of single-molecule trajectories with photoactivated localization microscopy, Nat. Methods. 5 (2008) 155. https://doi.org/10.1038/nmeth.1176.

[91] M.J. Saxton, Single-particle tracking: the distribution of diffusion coefficients, Biophys. J. 72 (1997) 1744-1753. doi:https://doi.org/10.1016/S00063495(97)78820-9.

[92] B.C. Hoffman, T. Mcafee, S. Pazoki, A. Apperson, B.T. O’Connor, D.B. Dougherty, Temperature controlled interlayer disorder in ultrathin films of $\alpha$ sexithiophene, Thin Solid Films. 642 (2017) 182-187. doi:https://doi.org/10.1016/j.tsf.2017.09.011.

[93] C. Reese, M. Roberts, M. Ling, Z. Bao, Organic thin film transistors, Mater. Today. 7 (2004) 20-27. doi:https://doi.org/10.1016/S1369-7021(04)00398-0.

[94] H. Tian, G. Boschloo, A. Hagfeldt, Molecular Devices for Solar Energy Conversion and Storage, Springer, 2018.

[95] L. Bartolini, M. Malferrari, F. Lugli, F. Zerbetto, F. Paolucci, P.G. Pelicci, C. Albonetti, S. Rapino, Interaction of Single Cells with 2D Organic Monolayers: A Scanning Electrochemical Microscopy Study, ChemElectroChem. 5 (2018) 29752981. doi:10.1002/celc.201800731.

[96] D. Nečas, P. Klapetek, Gwyddion: an open-source software for SPM data analysis, Cent. Eur. J. Phys. 10 (2012) 181-188. doi:10.2478/s11534-011-0096-2.

[97] B. Wang, S.P. Marchese-Ragona, T.C. Bristow, Roughness characterization of ultrasmooth surfaces using common-path interferometry, in: 1999: pp. 3617-3619. https://doi.org/10.1117/12.343706.

[98] H.-J.B. and M. Jaschke, Calculation of thermal noise in atomic force microscopy, Nanotechnology. 6 (1995) 1. http://stacks.iop.org/0957-4484/6/i=1/a=001. 